\title{
Seismic performance of MRFs with high strength steel main frames and EDBs
}

\author{
Ke Ke, Yiyi Chen ${ }^{* 1}$ \\ State Key Laboratory of Disaster Reduction in Civil Engineering, Tongji University, Shanghai 200092, \\ China
}

\begin{abstract}
An experiment was performed focusing on the seismic performance of a steel moment resisting frame (MRF) composed of high strength steel (HSS) members and energy dissipation bays (EDBs) with reduced beam section (RBS) beams. The behavior of the system is characterized by a damage-control stage with concentration of inelastic deformation in the energy dissipation bay (EDB), followed by a main-structural-damage stage with distributed plastification. Test results show that the system exhibits damage-control behavior and insignificant increase of residual drift in the damage-control stage. Even though the system is loaded to the stage in which inelastic deformations initiate at the main frame composed of high strength steel members, the system can deform in a ductile manner and the energy dissipation is stable. For further analysis of the system, the applicability of the trilinear kinematic hysteretic model is validated based on a proposed algorithm for idealizing the skeleton curve and the improved accuracy is achieved compared with the universally used bilinear model. Dynamic analyses are also performed based on prototype systems to validate the structural performance.
\end{abstract}

Keywords: steel moment resisting frames, high strength steel, energy dissipation bay, reduced beam section, damage-control, trilinear model, residual drift

\footnotetext{
$1 *$ Corresponding author. Tel.: +86-21-65982926; Fax: +86-21-65984976.

Email address: yiyichen@ tongji.edu.cn
} 


\section{Introduction}

Steel moment resisting frames (MRFs) have long been recognized as effective earthquake resistant systems. To ensure the survival of a structure under strong ground motions, the conventional design philosophy pursues reliable mechanisms and stable energy dissipation capacities of the system. Accordingly, to utilize the ductility of steel MRFs, beam ends, column bases and connections in a structure are allowed to develop inelastic deformations even simultaneously to balance the energy input of a strong ground motion. Although the life-safety goal can be achieved under intense earthquake events, a structure designed following this philosophy may sustain inelastic deformations in most members, and significant residual deformations are also unavoidable. Consequently, substantial property damage and economic loss due to repairing or demolishing work are expected, and this shortcoming was recognized in recent research works. For instance, Erochko et al. [1] found that the steel MRFs designed based on ASCE 7-05 would experience significant permanent residual drifts, and a system would have a high potential of being a total economic loss after even a design-level earthquake event. Also, conventional steel MRFs are more vulnerable to intense earthquakes since the positive post-yielding stiffness cannot be ensured up to the maximum expected drift, especially when the P-delta effect is significant [2-3], exposing the structures to risks of collapse. Therefore, it has been realized that tolerable residual drift, preferable nonlinear behavior and damage-control behavior [4] that restricts damages in target components are also important. Many efforts have been dedicated to innovative MRFs for seismic performance enhancement. For instance, to reduce the residual deformation, self-centering MRF 
structures implemented with post-tensioned [5] connections or shape memory alloy devices [6-7] were developed, and their excellent recentering behavior was validated by recent experimental investigations. To ensure continuously positive post-yielding stiffness of a steel MRF system, the concept of hybrid steel MRF system [2] in which plastic hinges can form in the expected sequence was proposed, and the improvement of seismic performance was observed in preliminary dynamic analyses. More recently, an innovative linked column frame system [8] was proposed to enhance the seismic performance of conventional steel MRFs, as damages can be restricted within the linked columns under earthquakes. In parallel with these studies, innovative compound steel MRFs installed with various energy dissipation devices or fuses [9-11] were investigated extensively, and they were able to achieve the expected damage-control behavior and controllable failure modes when subjected to an earthquake event.

This research explores the seismic performance of an innovative steel MRF structure: steel MRFs with high strength steel (HSS) members and energy dissipation bays (EDBs). Compared with some innovative systems that might be challenging due to complicated field construction efforts [12], the proposed system is practically attractive, and an appropriate combination of structural components could also provide sound seismic performance with reduced residual deformations and encouraging failure modes. In this investigation, the structural behavior is explored based on a cyclic experiment of a structural system, and the performance from yielding to failure is carefully investigated. In addition, an idealization approach to quantify the structural nonlinearity is proposed, and the applicability of the trilinear kinematic hysteretic model is validated by the test results. 
Based on a verified numerical model, dynamic analyses are also performed considering prototype structures, and the potential of the system is demonstrated.

\section{Design concept and noteworthy features of the system}

At its core, the proposed system is realized by combining mild carbon steel energy dissipation beams of reduced beam section (RBS) and high strength steel (HSS) members, as illustrated in Fig. 1. The system is practically attractive since no complicated field construction effort is required. The RBS beams are installed in a short bay designated as the energy dissipation bay (EDB) to achieve relatively larger stiffness and smaller yield drift, and the remaining frame composed of HSS members is designated as the main frame (MF), which is expected to be damage-free in the expected deformation range. Accordingly, early yielding of the energy dissipation bays (EDBs) and elastic behavior of main frames (MFs) can achieve a "damage-control stage". In the "main-structural-damage stage" in which the entire system develops inelastic deformation, the MF can also dissipate energy in a ductile manner. In this regard, multiple functions are assigned to the beams of EDBs, which behave as fuses for the early yielding behavior and service load carrying members simultaneously. Fig. 1 shows a typical load-displacement curve of the proposed system. Unlike conventional steel MRFs, for the proposed system, the yielding sequence reflected by trilinear behavior can be observed, and the trilinear kinematic hysteretic model can be used for quantifying the hysteretic feature, as shown in Fig. 2(a). The portion of the hysteretic curve defined as the "damage-control core" showing significant post-yielding stiffness ratio, guarantees concentration of damages in the EDBs in the damage-control stage. In addition, as schematically illustrated in Fig. 2(b), compared with a bilinear system 
that can represent a conventional steel MRF structure, in which the unloading stiffness is parallel to the initial slope, resulting relatively larger residual deformations, the damage-control core of the proposed system also produces a good recentering effect since the unloading path goes back closer to the origin, even though yielding of the MF occurs. In general, the improved seismic performance of the proposed steel MRF system is characterized by the following noteworthy features: (1) Damage-control behavior that restricts damages in target members is ensured in certain deformation range. (2) Multiple performance levels can be achieved. (3) Residual drifts are reduced.

\section{Test specimen}

The specimen was a large-scale welded frame with two stories and two bays. Two twin frames were connected by braces out of the frame plane.

\subsection{Dimensions}

The specimen had a plan dimension of $3 \mathrm{~m}$ in the longitudinal direction by $1 \mathrm{~m}$ in the transverse direction (Fig. 3(a)). In the longitudinal direction, the dimension of the EDB and MF was $1 \mathrm{~m}$ and $2 \mathrm{~m}$, respectively. The height from the column base to the roof level was $3.02 \mathrm{~m}$ with story height of $1.52 \mathrm{~m}$ and $1.50 \mathrm{~m}$ for the first and the second floor, respectively. The dimensions of the specimen and the detail of representative connections are illustrated in Fig. 3(b) and Fig. 3(c), respectively. The slenderness ratio of the column defined by the effective length of the column to the radius of gyration of the column section ratio in the frame plane direction ranged from 36 to 53, which can be regarded as the typical slenderness of steel MRF columns in engineering practice.

\subsection{Sections and connections}

The frame specimen was composed of welded H-section beams and columns. The 
nominal dimensions of the sections were $\mathrm{H} 140 \times 100 \times 12 \times 12$ for the beams of the MF, $\mathrm{H} 120 \times 120 \times 16 \times 16$ for the columns. For the EDB, the beams were $\mathrm{H} 205 \times 75 \times 4 \times 4$, and the RBS detail followed the AISC 358 [13] and Chinese Code for Seismic Design of Buildings (GB 50011-2010) [14], as given in Fig. 3(a). During the fabrication, all members in the frame were connected by full penetration welds, and specialized electrodes with a minimum tensile strength of $550 \mathrm{MPa}$ were used for the welds of connections in the MF with HSS members. Flaw detection and laser inspection procedures were also applied to control the quality of the welds. Note that as the primary objective of the experiment was to validate the design concept, the design of the specimen was conducted to ensure the yielding sequence of the structure, and a pre-analysis was performed to examine the yielding sequence of the system. Specifically, the moment distribution of the frame members was calculated by an elastic analysis when subjected to triangular lateral loads, and the moment normalized by the maximum is illustrated in Fig. 4(a). The values for beams correspond to the moments at the HSS beam ends and the centers of the RBS segments, respectively. The values for columns correspond to moments at the boundary of strengthening plates and column bases, respectively. A yielding factor is defined as

$$
\lambda=\frac{M}{M_{\mathrm{y}}}
$$

where $M$ is the moment calculated by the elastic analysis; $M_{\mathrm{y}}$ is the yielding moment denoting the initiation of plastification of members associated with the actual material property from coupon tests. The yielding factors normalized by the maximum value are given in Fig. 4(b). This index can be used to identify the first yielding components and roughly predict the yielding sequence. The relatively larger yielding factors of the EDB 
imply that beams in the EDB could yield earlier than other members. Essentially, the selection of structural dimensions, steel grades and member sections provided the possibility of adjusting the structural yielding sequence. For instance, although the moments of HSS beam end and the center of RBS at joint B (Fig. 4(a)) are almost identical, the difference of the yielding factors is significant (Fig. 4(b)), which is exactly due to the application of the HSS material and the RBS segment of carbon mild steel in the MF and the EDB, respectively. In this regard, although sections of the MF members for the test specimen are not universally used in practical cases, the concept of the system could be realized, and thus the structural behavior of the specimen is also of engineering value.

\subsection{Material}

The steel grades for the RBS beams in the EDB and the HSS members in the MF were Q235B with a nominal yield stress of $235 \mathrm{MPa}$ and Q460C with a nominal yield stress of $460 \mathrm{MPa}$, respectively. Fig. 5 presents the results of coupon tests in terms of the engineering stress-strain curves extracted from all tensile coupons, and the mechanical properties are given in Table 1.

\section{Test setup and loading program}

Fig. 6 shows the test setup. The specimen was fixed on the ground via a rigid foundation beam. Two actuators mounted on a loading machine were connected to two horizontal loading beams in each story for applying cyclic loads on the specimen. Since the loading beams were installed at the midline of axis a and $b$ (Fig. 6) with pinned connections, the loads applied on each frame were theoretically identical, which was also validated by the strain data monitored during the test. To involve the effect of vertical loads, a vertical load distributing system composed of a primary beam and secondary beams connected to an 
actuator in the vertical direction was also developed, and the load exerted from the vertical actuator was transferred to the columns with pinned connections.

In the experiment, the constant vertical load of $2500 \mathrm{kN}$, was firstly applied on the specimen to simulate the vertical loads caused by gravity. This vertical load was equivalent to a nominal axial force ratio $\left(N / N_{\mathrm{y}}\right)$ of 0.27 regarding the middle columns, where $N$ and $N_{\mathrm{y}}$ are the axial force and the nominal axial force causing yielding of the column, respectively. Then, the cyclic horizontal loads were applied on each story to simulate seismic actions, and the triangular load distribution mode was adopted during entire load cycles, which was realized by a servo-controlling system to keep the ratio of the horizontal loads as 1:2 (1 for the first story and 2 for the second story, respectively). Fig. 7 shows the loading protocol, which was modified based on AISC 341-10 [15] by inserting the amplitude of $0.2 \%, 1.25 \%$ and $1.75 \%$, in order to investigate the performance of the system under various drifts for validation of the noteworthy features and to trace residual drifts. The quasi-static cyclic loading with increasing drifts was adopted and two cycles were repeated for each amplitude. After serious strength deterioration was observed, the specimen was pushed over eventually. During the test, the measured story drifts determined by displacement transducers were used for controlling the cyclic amplitudes. Since the drift of the second story would be larger as observed in the pre-analysis, it was used to govern the load cycles.

\section{Measurement}

Responses of the specimen were monitored and measured by force sensors, strain gauges, and displacement transducers. Fig. 8 illustrates the arrangement of stain gauges 
and story displacement transducers. To monitor inception of yielding and to trace inelastic deformation development of members, strain gauges were arranged at the ends of members. In addition, to obtain the internal forces (axial forces, shear forces and moments) evolution, for each column and HSS beam, four strain gauges were glued at two cross-sections in the middle of the member, respectively, which were expected to remain elastic up to the drift of $4 \%$ during load cycles. Therefore, the column axial force could be calculated based on the average value of the data captured by the strain gauges. The moments at the elastic cross sections with strain gauges could be derived based on the plane cross-section assumption with the recorded strain data, and the shear force in the column could be determined by the sum of the two bending moments of the elastic cross-sections divided by the distance between the measured cross-sections. In-plane displacement transducers were arranged at two twin frames in each story and foundation beams to measure the story drift. Out-of-plane floor displacements in the transverse direction were also monitored with the corresponding displacement transducers during load cycles. 216 strain gauges and 12 displacement transducers in total were arranged on the specimen, and all these data were continuously recorded every $0.1 \mathrm{~s}$ by a data acquisition system.

\section{Test results}

\subsection{Damage evolution and failure mode}

With the drifts increasing, slight local buckling was firstly detected in the beams of the EDB when the drift reached $1.5 \%$. After the drift amplitude reaching 4\%, visible lateral deformation of the beams in the EDB and cracking initiated at the RBS region and HSS beam-to-column connections were observed. The failure mode characterized by fractures of both RBS beams and HSS beams, global instability of the RBS beams in the EDB and 
inclination of the frame is illustrated in Fig. 9, after the specimen was loaded to the drift of $8 \%$.

\subsection{Yielding sequences and damage-control behavior}

Strain readings were extracted, and representative data in the frame of Axis a (the substructure in Fig. 10) are illustrated in Fig. 11. In the figure, $V_{1}$ denotes the shear force of the first story; $\varepsilon_{\mathrm{yRBS}}, \varepsilon_{\mathrm{yb}}$ and $\varepsilon_{\mathrm{yc}}$ are the yielding strain of the RBS beam, the yielding strain of the HSS beam and the yielding strain of the HSS column base, respectively. The favorable yielding sequence is indicated by the hysteretic loops of strain data. Specifically, the EDB initiated yielding at the drift of $0.5 \%$ and developed sufficient inelastic deformation at the drift of $1.25 \%$. Comparatively, the HSS beam and the column base initiated inelasticity at the drift of $1.5 \%$ and $2 \%$, respectively. However, the record of RBS beam strains became erratic when the story drift reached $3 \%$, and it is believed to be unreliable due to the possible damage of strain gauges.

To clarify the damage-control behavior, the moment development during load cycles was derived according to the strain data in the elastic cross-sections, based on the force equilibrium regarding the representative joints (Fig. 10). The moments at members end $(M)$ versus the story drift $\left(\theta_{1}\right)$, considering the joints in the first story of "Axis a" are presented in Fig. 12. When the controlled drift reached 1.5\%, the HSS members of the MF almost stayed elastic, which is indicated by the almost linear moment responses, while the RBS beams had formed plastic hinges and developed significant inelastic deformations (Fig. 12(a)). Therefore, the damage-control behavior was successfully achieved. With the drift amplitude increasing to $3 \%$, the synergetic energy dissipation behavior was still satisfactory, as illustrated in Fig. 12(b). At this load amplitude, although the 
damage-control behavior did not hold, the HSS members were contributing to the energy dissipation in stable and ductile manner. Also, slight degradation caused by global and local instability of the RBS beams in the EDB occurred at this drift. In practice, this degradation can be effectively prevented with more compact sections and out-of-plane braces if larger ductility demand should be satisfied.

\subsection{Hysteretic responses for validation of multiple performance levels}

Hysteretic responses of two stories in terms of story shear force-story drift curves are shown in Fig. 13. $V_{1}$ and $V_{2}$ are the shear forces of the first and the second story, respectively, and $\theta_{1}, \theta_{2}$ are the corresponding story drifts. According to the results, multiple performance levels can be observed. Specifically, the damage-control core (within $\pm 1.5 \%$ drift) showing significant post-yielding stiffness, which was provided by the elastic MF, is identified in the hysteretic curves. When the deformation of the specimen was restricted in this core, the inelastic damages were mostly concentrated in the EDB, which is also clarified by the data in Section 6.2. When the drift increased and the MF developed sufficient inelasticity, the rapid degradation of the post-yielding stiffness occurred, but the desired ductile performance could still be achieved, as shown by the stable story shear force-drift hysteretic loops. The skeleton curves describing the maximum value of the shear force for each drift amplitude till $4 \%$ are illustrated in Fig. 14, and the associated damage phenomena are also clarified. The trilinear behavior can be observed, validating the successfully achieved multiple performance levels.

The absorbed energy responses calculated by the external work of horizontal loads are plotted in Fig. 15, in which the energy absorbed in each load cycle and accumulated in all load cycles are both addressed. The equivalent viscous damping given by Equation (2) 
indicating the energy dissipation of the specimen is also calculated and illustrated in Fig. 16.

$$
\xi_{\mathrm{e}}=\frac{1}{2 \pi} \frac{S_{A B C}+S_{A D C}}{S_{O B E}+S_{O D F}}
$$

where $S_{\mathrm{ABC}}$ and $S_{\mathrm{ADC}}$ are the areas covered by curve $\mathrm{ABC}$ and $\mathrm{ADC}$, respectively; $S_{\mathrm{OBE}}$ and $S_{\mathrm{ODF}}$ are the areas covered by OBE and ODF, respectively (Fig. 16 (a)). It is noted that the absorbed energy responses show remarkable trilinear feature, which is due to an energy dissipation mode transformation caused by the multiple performance levels. Specifically, a concentrated energy dissipation mode was firstly formed when the RBS beams yielded and dissipated energy. With drift increasing, a distributed energy dissipation mode was then achieved since the system developed yielding in all members. This behavior is also indicated by the equivalent damping, as a rapid increase of the damping can be observed at larger drifts (Fig. 16(b)).

\subsection{Residual drift responses}

Residual drift responses are plotted considering both loading directions and given in Fig. 17. The residual drift is defined as the drift when the external lateral forces were unloaded to zero, and it is the maximum possible residual drift [16-17] for a system subjected to an earthquake. With the load amplitude increasing, the growth of the residual drifts was insignificant in a large deformation range. Even though the specimen was loaded to the drift of $2 \%$, which is generally regarded as the drift limit [14], the residual drift was merely around $0.5 \%$. Interestingly, this value is generally taken as the resilience threshold [1], since if the residual drift is above it, a structure is considered to be a total economic loss as the cost of repair work might be more significant than demolishing it. 


\section{Analysis and discussion}

\subsection{Quantification and validation of the trilinear kinematic hysteretic model}

To identify the damage-control behavior and the multiple performance levels of the proposed system, a key issue comes down to the quantification and validation of the trilinear kinematic hysteretic model, which is exactly the essence of the noteworthy features of the proposed system. Generally, the bilinear models and the perfectly elasto-plastic idealization approach illustrated in Fig. 18 are adopted in current seismic performance evaluation procedures. Therefore, an equivalent ductility $(\mu)$ and a post-yielding stiffness ratio $(\alpha)$ are taken as the basic parameters, and pushover analysis approaches documented in various codes [18-20] were established based on these simplifications. However, for the proposed system showing trilinear behavior, these models would not be able to quantify the damage-control stage and the multiple performance levels. Accordingly, a trilinear idealization approach is proposed.

As illustrated in Fig. 19, instead of using the ductility factor, two sequence factors are defined and expressed as

$$
\begin{gathered}
\zeta_{\mathrm{T}}=\frac{\delta_{\mathrm{T}}}{\delta_{\mathrm{y} 1}} \\
\zeta_{1}=\frac{\delta_{\mathrm{y} 2}}{\delta_{\mathrm{y} 1}}
\end{gathered}
$$

where $\delta_{\mathrm{y} 1}, \delta_{\mathrm{y} 2}$ and $\delta_{\mathrm{T}}$ are the equivalent yield displacement of EDBs, the equivalent yield displacement of the MF and the target displacement, respectively. Therefore, the trilinear nonlinear behavior can be quantified based on the sequence factors associated with the corresponding post-yielding stiffness ratios $\left(\alpha_{1}\right.$ and $\left.\alpha_{2}\right)$. 
Note that in practice a structural nonlinear curve is not completely trilinear since components would not yield simultaneously in different stages, and a critical issue lies in an applicable algorithm for quantifying the trilinearity based on a practical pushover curve and determining the turning points. In this work, an iteration procedure governed by the least square principle is proposed. Specifically, the data extracted from a nonlinear curve (skeleton curve or pushover curve) are firstly normalized, given by

$$
\begin{gathered}
\lambda=\frac{\chi}{\chi_{\max }} \\
\eta=\frac{F}{F_{\max }}
\end{gathered}
$$

where $\chi$ and $\chi_{\max }$ denote the displacement and the maximum displacement, respectively; $F$ and $F_{\max }$ denote the force and the maximum force, respectively. The maximum displacement and the corresponding force are preselected based on an experiment or a pushover analysis, which can be associated with the ultimate state of the system. Then, the idealized multi-linear function can be expressed as

$$
H=\left\{\begin{array}{lc}
k \lambda & 0 \leq \lambda \leq \lambda_{1} \\
\alpha_{1} k \lambda+\left(1-\alpha_{1}\right) k \lambda_{1} & \lambda_{1}<\lambda \leq \lambda_{2} \\
\alpha_{2} k \lambda+\left(\alpha_{1}-\alpha_{2}\right) k \lambda_{2}+\left(1-\alpha_{1}\right) k \lambda_{1} & \lambda_{2}<\lambda \leq 1
\end{array}\right.
$$

where $H$ denotes the target function quantifying the trilinearity; $k$ stands for the initial stiffness of the normalized idealized curve, which can be predetermined with an elastic analysis; $\lambda_{1}$ and $\lambda_{2}$ denote the displacements of turning points in the idealization, representing the equivalent yield point of the EDBs and the MF, respectively. The governing function is then expressed as

$$
\begin{aligned}
& \left.S=\sum_{i=1}^{M}\left(k \lambda_{i}-\eta_{i}\right)^{2}+\sum_{i=M+1}^{M+N}\left[\alpha_{1} k\left(\lambda_{i}-\lambda_{1}\right)+k \lambda_{1}-\eta_{i}\right)\right]^{2}+ \\
& \left.\sum_{i=M+N+1}^{M+N+Q}\left[\alpha_{2} k\left(\lambda_{i}-\lambda_{2}\right)+\alpha_{1} k\left(\lambda_{2}-\lambda_{1}\right)+k \lambda_{1}-\eta_{i}\right)\right]^{2}
\end{aligned}
$$


where $M$ denotes the number of data points in the elastic stage; $N$ denotes the number of data points in the damage-control stage; $Q$ denotes the number of data points in the main-structural-damage stage. The target function can be consequently determined when $S$ achieves the minimum value. Note that although the turning points solved are equivalent yield points with no exact physical meaning, this idealization is still more tenable compared with current approaches as it captures the trilinear nature of the system.

With the trilinear idealization approach, the applicability of the classical trilinear kinematic hysteretic model can be validated based on the experimental displacement history. Specifically, Equation (8) is first applied to skeleton curves to determine the post-yielding stiffness ratios, the equivalent yield drift of the EDB and the MF, and the sequence factors. Then, the drift history extracted from the test results database are used to obtain the trilinear kinematic hysteretic model curve associated with the determined coefficients following the trilinear kinematic hysteretic law, and the applicability of the hysteretic law can be evaluated by comparing the model curve with the test curve. Since fractures of multiple members occurred when the specimen was loaded to the drift of $4 \%$, hysteretic curves corresponding to the maximum drift of $3 \%$ are used for comparison. The bilinear model from ATC-40 is also applied. The obtained model curves corresponding to the bilinear and trilinear kinematic hysteretic model are compared with test curves, and the results of two stories are shown in Fig. 20. The corresponding coefficients are also addressed in the figure. In particular, $\theta_{\mathrm{y} 1}$ and $\theta_{\mathrm{y} 2}$ are the determined equivalent yield drift of the EDB and the MF in the corresponding story from the trilinear model, and $\theta_{\mathrm{y}}$ is the equivalent yield drift determined by the bilinear model. According to these results, the 
improved accuracy of the trilinear model is evident. In contrast, the bilinear model cannot involve the multiple yielding stages and the transformation of hysteretic behavior, and the damage-control core cannot be quantified either.

Based on the trilinear model, the theoretical maximum residual displacement is derived and given by Equation (9). The precondition of Equation (9) is $\alpha_{1}\left(\zeta_{\mathrm{T}}-1\right)>1$, which leads to the yielding of EDBs during unloading. Note that when the displacement is restricted in the damage-control core, the calculation of the residual displacement is the same as a bilinear system. The residual drift responses determined from the trilinear model and the bilinear model are also given in Fig. 21. The improved accuracy of the trilinear model is demonstrated again. In addition, the rapid growth of residual drifts indicated by the bilinear model which can represent conventional steel MRFs implies that these systems might not be functionally recoverable since the residual deformation is not controllable.

$$
\delta_{\mathrm{rm}}= \begin{cases}\left(1-\alpha_{1}\right)\left(\zeta_{\mathrm{T}}-1\right) \delta_{\mathrm{y} 1} & 1<\zeta_{\mathrm{T}} \leq 1+\frac{1}{\alpha_{1}} \\ \frac{\left(1-\alpha_{1}\right)}{\alpha_{1}} \delta_{\mathrm{y} 1} & 1+\frac{1}{\alpha_{1}}<\zeta_{\mathrm{T}} \leq \zeta_{1} \\ {\left[\frac{\left(1-\alpha_{1}\right)}{\alpha_{1}}+\left(\zeta_{\mathrm{T}}-\zeta_{1}\right)\left(\frac{\alpha_{1}-\alpha_{2}}{\alpha_{1}}\right)\right] \delta_{\mathrm{y} 1}} & \zeta_{\mathrm{T}}>\zeta_{1}\end{cases}
$$

\subsection{Analyses of preliminarily designed prototype structures}

To further demonstrate the satisfactory seismic behavior of the proposed system under ground motions, dynamic analyses are also performed on prototype structures. The numerical model established with Perform3D [21] is firstly calibrated based on the test results. Specifically, the specimen is modeled with frame compound components with stiff end zone. For the EDB, beams with RBS segments are modeled with elastic frame segments and zero length plastic hinges, considering both location and reduced plastic 
strength with $2 \%$ hardening ratio. For the MF, the inelastic fiber hinge method [22] is adopted and the bilinear uniaxial material model with $2 \%$ hardening ratio is assumed. The fiber segment length is assumed to be $4 \%$ of the member length [22] (Fig. 22(a)). In the model, the stiffness of panel zones is not considered with the assumption of rigid joint, which is rational since the panel zones of the specimen were strengthened. During the modeling, fracture, instability and cyclic degradation of components are not considered. Therefore, each loading amplitude is considered for one cycle to facilitate the analysis procedure, and the analysis is terminated when the controlled drift reaches the amplitude of $4 \%$. The comparison of the experiment result and the numerical simulation in terms of the cyclic response and skeleton curves is given in Fig. 22(b) and Fig. 22(c). The satisfactory agreement between the experimental data and the numerical results indicates that the modeling of the system is rational.

Two 6-story frame systems are preliminarily designed and modeled based on the validated approach. A dead load of $4.8 \mathrm{kN} / \mathrm{m}^{2}$ and a live load of $2 \mathrm{kN} / \mathrm{m}^{2}$ are assumed. For Frame A, the beams are designed with mild carbon steel with a yield stress of $235 \mathrm{MPa}$ and columns of $345 \mathrm{MPa}$. The RBS sections are not involved. For Frame B, the EDB is designed with RBS beams considering the material yield stress of $235 \mathrm{MPa}$ and the MF is designed with HSS of $460 \mathrm{MPa}$, which can be a representative system proposed in this research. The design of Frame $\mathrm{B}$ is achieved by an iteration procedure based on the residual deformation feature of the system. As indicated by Section 7.1, if the parameters of the damage-control core satisfy $\alpha_{1}\left(\zeta_{\mathrm{T}}-1\right)>1$, yielding of EDBs would be triggered during the unloading (Figure 2(b)), leading to further reduction of residual deformations. 
Specifically, this criterion could be quantified in terms of the yield base shear of the system, and given by

$$
\frac{V_{\text {yMF }}}{V_{\text {yEDB }}}>2
$$

where $V_{\mathrm{yMF}}$ and $V_{\mathrm{yMF}}$ are the base shear forces corresponding to the yielding of the MF and the EDBs, respectively. These features can be confirmed by applying the proposed idealized approach to the pushover curve, and the design of the EDBs and the MF could be completed during the iteration. The detail of the RBS sections of the EDBs is illustrated in the Fig. 23(a), satisfying the requirement of AISC 358 [13] and Chinese Code for Seismic Design of Buildings (GB 50011-2010) [14]. For these sections, the strength reduction in terms of the plastic moment capacity is around 50\%. During the design, the basic acceleration is assumed to be $0.4 \mathrm{~g}$, and the design spectrum is given in Fig. 23(b). It should be noted that since the primary objective of designing the prototype structures is to verify the excellent response of the proposed system and to compare its behavior with a conventional steel MRF system, the structural members of Frame B are designed to be identical to Frame A. The members information and the elastic vibration property are illustrated in Fig. 23(a). In the modeling procedure, the Rayleigh damping of 5\% is assumed.

The pushover-unloading curve (push to roof drift of $2 \%$ ) of the systems considering the fundamental vibration mode is illustrated in Fig. 24(a), in which $V_{\mathrm{b}}$ and $W$ denote the base shear and gravity load, respectively. As a conventional steel MRF system showing the typical bilinear behavior, Frame A develops entirely yielding after the roof drift reaching around $1 \%$, followed by negligible post-yielding stiffness. Comparatively, the 
damage-control behavior of Frame B results in favorable significant post-yielding stiffness [16-17, 23] up to roof drift of $1.5 \%$ approximately with significantly higher ultimate strength, and the reduction in maximum residual drift is also significant. This is due to the strength gap between the MF of HSS members and the EDBs with RBS beams. For instance, at the roof drift of $2 \%$, the moment ratio of the beams in the EDB and the MF at joint K (Fig. 23(a)) in Frame B can achieve 1:2.92, while the value for Frame A is only 1:1.31. More importantly, the evident enhancement of the MF in Frame B does not require heavier sections since the weight and elastic stiffness of the structure are almost the same as Frame A, which will not increase the earthquake demand.

20 ground motions developed in the original SAC project (LA01-LA20) [24] are used as excitations. The comparison of the mean spectrum and the design spectrum is shown in Fig. 23(b), validating the applicability of the adopted ground motions. Maximum story drift responses and residual story drift responses (the drifts extracted after 100s of vibration following the input ground motion) considering the median value are illustrated in Fig. 24(b) and Fig. 24(c), respectively. These results indicate that the application of HSS members would not necessarily increase the maximum drift demand since the median responses of the two systems are almost identical. However, the residual drift responses of Frame B are significantly smaller than those of Frame A. Maximum drift responses and residual drift responses of systems considering all stories and all ground motions are clarified in Fig. 24(d) and Fig. 24(e). In the figure, the horizontal coordinate of every point is the response of Frame $\mathrm{B}$ and the vertical coordinate corresponds to the response of Frame A in the same story under an individual ground motion. These results imply that the 
maximum drift responses are not sensitive to structural nonlinearity as the data points are clustered at the diagonal line. In contrast, the effect of the structural nonlinear feature on the residual drift is significant, since almost all residual drifts of Frame B are smaller than the corresponding responses of Frame A. Therefore, the potential of the proposed system is validated dynamically. Although the complete design procedure requires more explorations, the satisfactory response of Frame $\mathrm{B}$ implies that the iteration procedure presented above is applicable for obtaining a satisfactory preliminary design strategy of the proposed system, using the design of a conventional steel MRF as a start point.

It should be pointed out that HSS members and the corresponding welding connections generally do not reserve adequate inelastic deformation capacity as carbon mild steel does, which might be a challenge for their applications in earthquake resistant structures. Even though the excellent energy dissipation of the HSS MF was achieved, which was observed in the test and validated in relevant research works [25-28], the limited ductility of HSS material and the welds should be considered carefully. In this context, since analyses indicate that the application of the HSS MF does not necessarily lead to increase of maximum responses, following the equal-displacement rule [29-30] for multi-story steel MRFs in the long period region, it is convenient to control the maximum inelastic deformation of the HSS members and connections in design by making use of their satisfactory elastic deformation capacity. This is reinforced by the dynamic analysis results that the maximum tension strain in the inelastic fiber hinge of the MF is only $13.9 \%$ (during ground motion of LA09) for the Frame B, meaning that there would be no failure of HSS members or welds when the fabrication quality is ensured. 


\section{Conclusions}

An innovative steel moment resisting frame (MRF) structure composed of high strength steel (HSS) members as the main frame (MF) and energy dissipation bays (EDBs) with reduced beam section (RBS) beams of mild carbon steel was tested. Theoretical analyses are also performed and the favorable seismic performance of the system is clarified. The following findings can be drawn from this study:

1. The excellent damage-control behavior compared with conventional steel MRF systems was observed when the drift loading amplitude was not significant. In particular, the concentration of damages in the energy dissipation bay and the insignificant increase of residual drifts in the damage-control stage were achieved.

2. The favorable ductile manner of the system was achieved when the system was loaded to significant drifts at which the high strength steel members in the main frame developed sufficient inelastic deformations. The stable hysteretic response and the satisfactory energy dissipation validate the sound seismic performance of the system in the main-structural-damage stage.

3. Compared with a bilinear model which is widely used, the trilinear kinematic hysteretic model is demonstrated to be more tenable for quantifying the structural behavior considering the proposed system. A trilinear idealization approach for quantifying structural nonlinearity is also proposed for practical application, and the improved accuracy is validated by the experimental data.

4. Based on a validated numerical model, dynamic analyses are performed considering the seismic response of preliminarily designed prototype structures, and the satisfactory 
behavior of the system is clarified dynamically.

A complete verification of the proposed system still relies on the consideration of inelastic earthquake demands and the arrangement criteria of the structural members. Currently, the shaking table test, investigations regarding the performance-based design approaches are in progress. Moreover, works regarding the improvement of the system, such as the implementation of replaceable energy dissipation bays and innovative high strength steel members connections which are less susceptible to fracture are ongoing. They will provide full validation of the proposed system for practical applications.

\section{Acknowledgments}

This research is supported by the National Science Foundation of China (Grant No. 51038008) and the Ministry of Science and Technology of China (Grant No. SLDRCE 14-A-03).

\section{References}

[1] Erochko J, Christopoulos C, Tremblay R, Choi H. Residual drift response of SMRFs and BRB frames in steel buildings designed according to ASCE 7-05. Journal of Structural Engineering 2011; 137(5): 589-599.

[2] Charney FA, Atlayan O. Hybrid moment-resisting steel frames. Engineering Journal 2011; 48(3): 169-182.

[3] Gupta A, Krawinkler H. Dynamic P-delta effects for flexible inelastic steel structures. Journal of Structural Engineering 2000; 126(1): 145-154.

[4] Connor JJ, Wada A, Iwata M, Huang, YH. Damage-controlled structures .1. preliminary design methodology for seismically active regions. Journal of Structural 
Engineering 1997; 123(4): 423-431.

[5] Lin YC, Sause R, Ricles JM. Seismic performance of a large-scale steel self-centering moment-resisting frame: MCE hybrid simulations and quasi-static pushover tests. Journal of Structural Engineering 2013; 139(7SI): 1227-1236.

[6] Fang C, Yam MCH, Lam ACC, Xie LK. Cyclic performance of extended end-plate connections equipped with shape memory alloy bolts. Journal of Constructional Steel Research 2014; 94:122-136.

[7] Yam MCH, Fang C, Lam ACC, Zhang YY. Numerical study and practical design of beam-to-column connections with shape memory alloys. Journal of Constructional Steel Research 2015; 104:177-192.

[8] Malakoutian M, Berman JW, Dusicka P. Seismic response evaluation of the linked column frame system. Earthquake Engineering and Structural Dynamics 2013; 42(6): 795-814.

[9] Vargas R, Bruneau M. Experimental response of buildings designed with metallic structural fuses. II. Journal of Structural Engineering; 2009, 135(4): 394-403.

[10]Calado L, Proença JM, Espinha M, Castiglioni CA. Hysteretic behaviour of dissipative bolted fuses for earthquake resistant steel frames. Journal of Constructional Steel Research 2013; 85: 151-162.

[11]Dougka G, Dimakogianni D, Vayas I. Innovative energy dissipation systems (FUSEIS 1-1) - experimental analysis. Journal of Constructional Steel Research 2014; 96: 69-80.

[12]Lin Y. Behavior of a steel coupled beam moment frame based on nonlinear analyses. Journal of Constructional Steel Research 2014; 99: 10-17. 
[13]AISC. Prequalified Connections for Special and Intermediate Steel Moment Frames for Seismic Applications, ANSI/AISC 358-10. American Institute for Steel Construction: Chicago, IL, 2010.

[14]CMC. Code for seismic design of buildings (GB 50011-2010). China Ministry of Construction: Beijing, 2010

[15] AISC. Seismic provisions for structural steel buildings, ANSI/AISC 341-10. American Institute for Steel Construction: Chicago, IL,2010.

[16]Kawashima K, Macrae GA, Hoshikuma J, Nagaya K. Residual displacement response spectrum. Journal of Structural Engineering 1998; 124(5): 523-530.

[17]Macrae GA, Kawashima K. Post-earthquake residual displacements of bilinear oscillators. Earthquake Engineering and Structural Dynamics 1997; 26(7): 701-716.

[18]CEN. EuroCode 8: design provisions for earthquake resistance-Part 1: general rules, seismic actions and rules for buildings. European Committee for Standardization: Brussels, 2004.

[19]Applied Technology Council. Seismic evaluation and retrofit of concrete buildings ATC-40: Redwood City,1996.

[20]Federal Emergency Management Agency. NEHERP provisions for the rehabilitation of buildings. FEMA No.273 (Guidelines) and 274 (Commentary), Washington, DC, 1997.

[21]CSI. PERFORM-3D v4.0.3 nonlinear analysis and performance assessment for 3D structures. California, USA: Computers and Structures Inc.; 2006.

[22]Cuong NH, Kim SE. Practical advanced analysis of space steel frames using fiber 
hinge method. Thin Walled Structures 2009; 47(4): 421-430.

[23]Nakashima M, Saburi K, Tsuji B. Energy input and dissipation behavior of structures with hysteretic dampers. Earthquake Engineering and Structural Dynamics 1996; 25(5): 483-496.

[24] Shome N, Cornell CA, Bazzurro P, Carballo JE. Earthquakes, records, and nonlinear responses. Earthquake Spectra 1998; 14(3): 469-500.

[25]Green PS, Sause R, Ricles JM. Strength and ductility of HPS flexural members. Journal of Constructional Steel Research 2002; 58(5-8): 907-941.

[26] Wang Y, Li G, Cui W, Chen S, Sun F. Experimental investigation and modeling of cyclic behavior of high strength steel. Journal of Constructional Steel Research 2015;104: 37-48.

[27] Sause R, Fahnestock L. Strength and ductility of HPS-100W I-girders in negative flexure. Journal of Bridge Engineering 2001; 6(5): 316-323.

[28]Chen YY, Sun W, Chan TM. Cyclic stress-strain behavior of structural steel with yield strength up to $460 \mathrm{~N} / \mathrm{mm} 2$. Frontiers of Structural and Civil Engineering 2014; (8)2: 178-186.

[29]Newmark NM, Hall WJ. Earthquake Spectra and Design. Earthquake Engineering Research Institute: Berkeley, CA, 1982.

[30]Leelataviwat S, Saewon W, Goel SC. Application of energy balance concept in seismic evaluation of structures. Journal of Structural Engineering 2009; 135(2): $113-121$ 
Table 1 . The results of coupon test

\begin{tabular}{ccccc}
\hline & Steel & Yield & Ultimate \\
sthickness/mm & $\begin{array}{c}\text { Elongation } \\
f_{\mathrm{y}} / \mathrm{MPa}\end{array}$ & $\begin{array}{c}\text { strength } \\
f_{\mathrm{u}} / \mathrm{MPa}\end{array}$ & $\Delta / \%$ \\
\hline 16 & $\mathrm{Q} 460 \mathrm{C}$ & 587 & 642 & 22.2 \\
\hline 12 & $\mathrm{Q} 460 \mathrm{C}$ & 504 & 575 & 21.8 \\
\hline 4 & $\mathrm{Q} 235 \mathrm{~B}$ & 338 & 459 & 36.3 \\
\hline
\end{tabular}




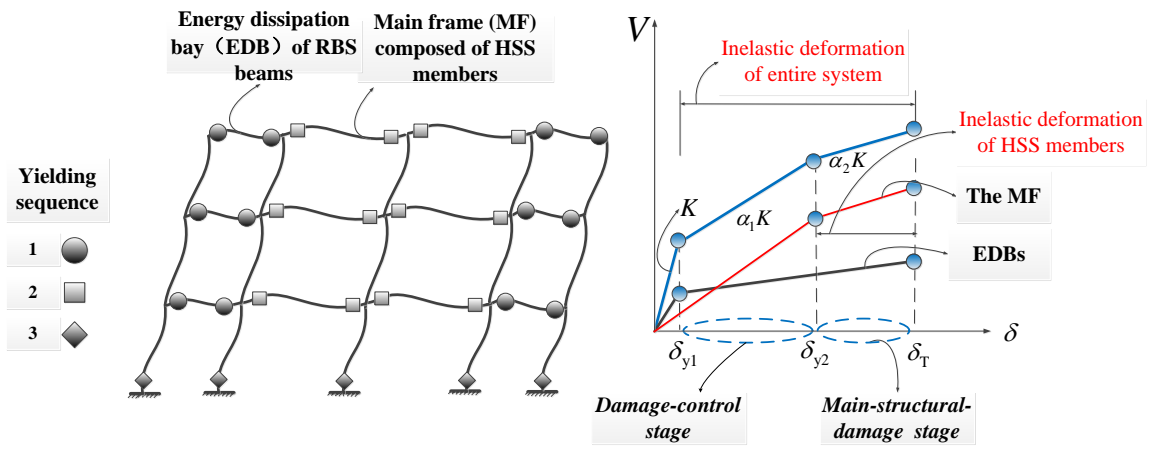

Fig. 1. Design concept and loading bearing behavior of the system.

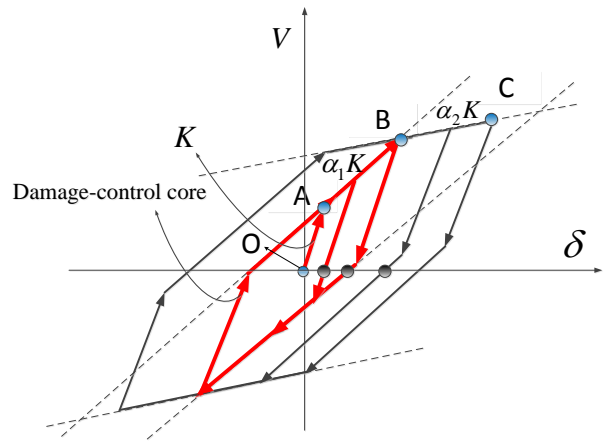

(a)

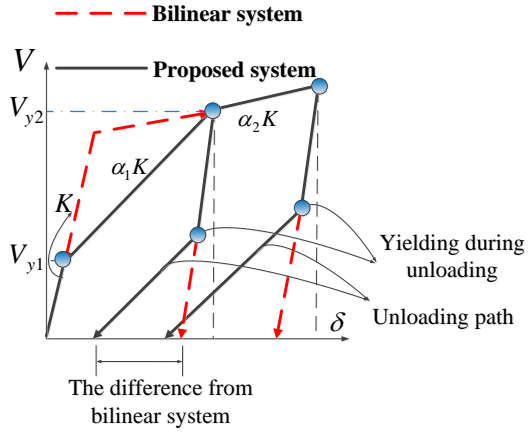

(b)

Fig. 2. Trilinear hysteretic behavior: (a) Trilinear kinematic hysteretic model, (b) Residual deformation reduction.

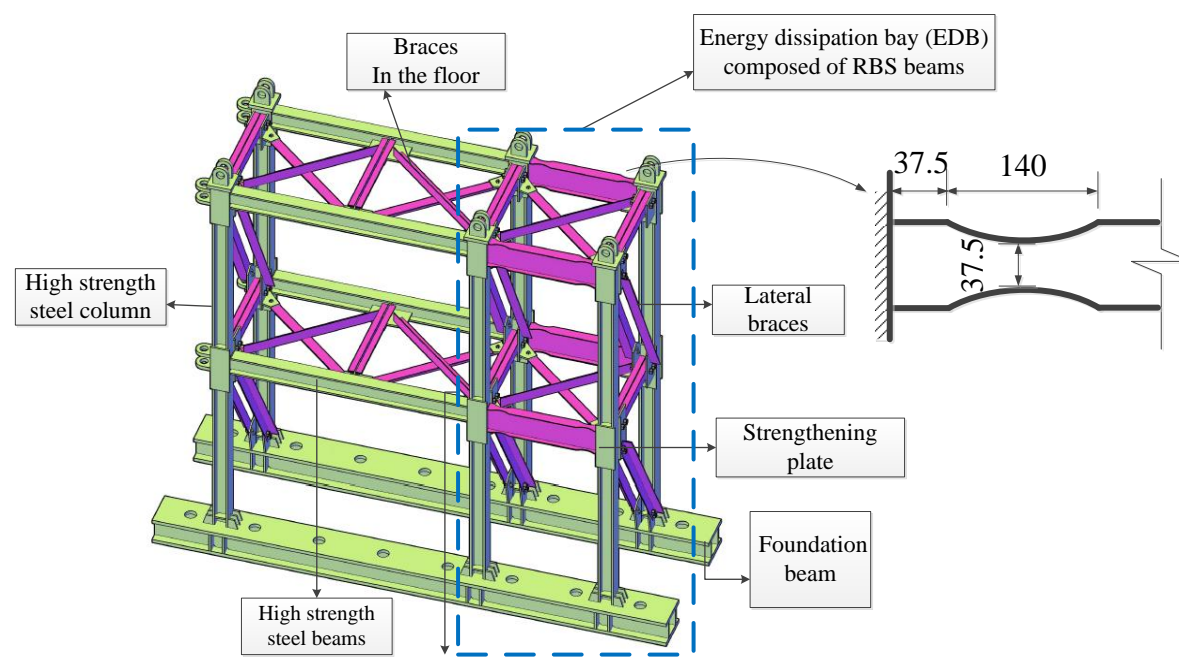

(a) 


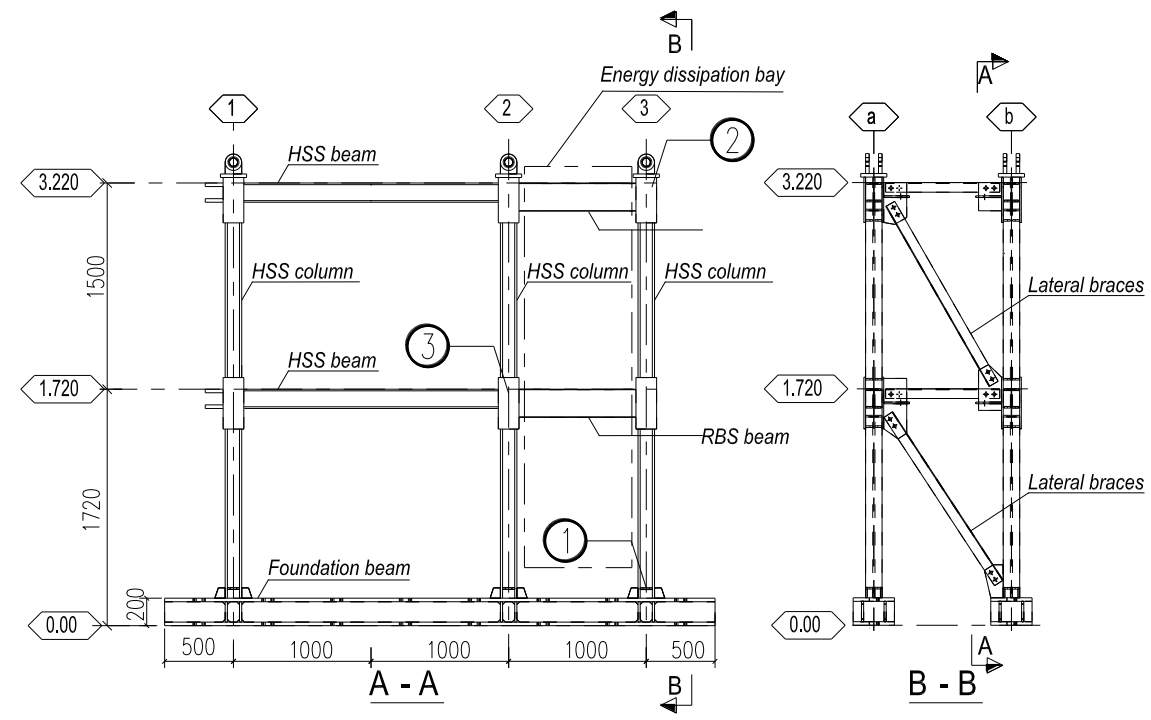

(b)
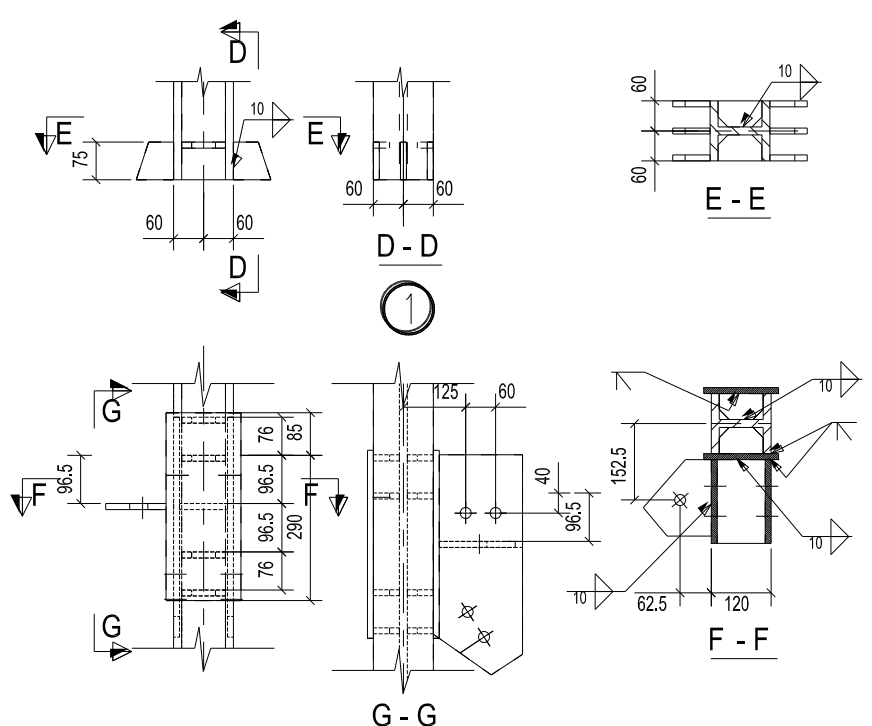

(2)

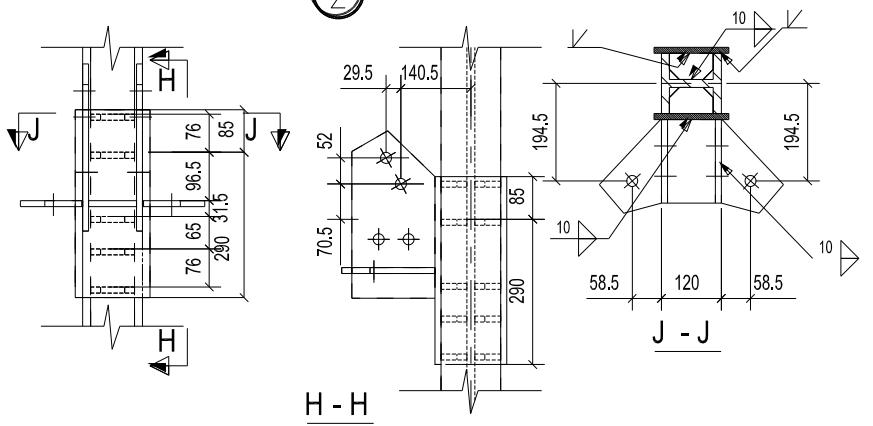

(3)

(c)

Fig. 3. Information of the test frame: (a) 3D view, (b) Dimension of the tested frame, (c) Representative connections. 


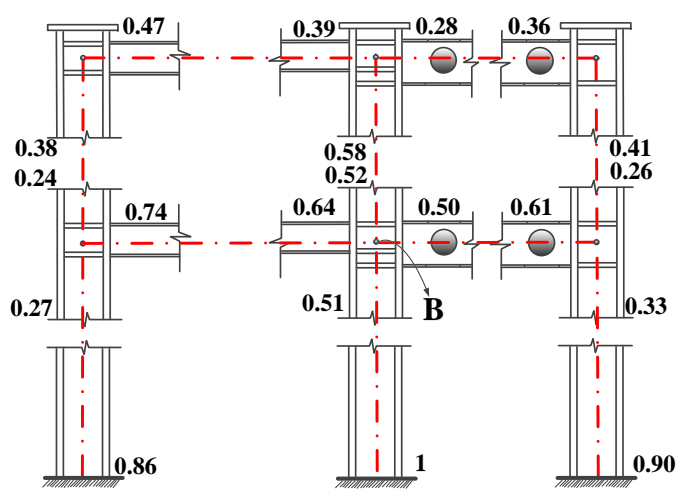

(a)

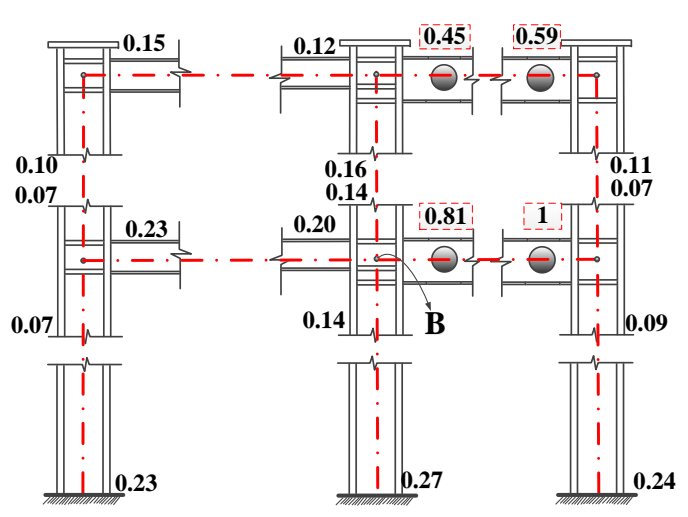

(b)

Fig. 4. Normalized moment distribution and yielding factor: (a) Normalized elastic moment distribution, (b) Yielding factor.
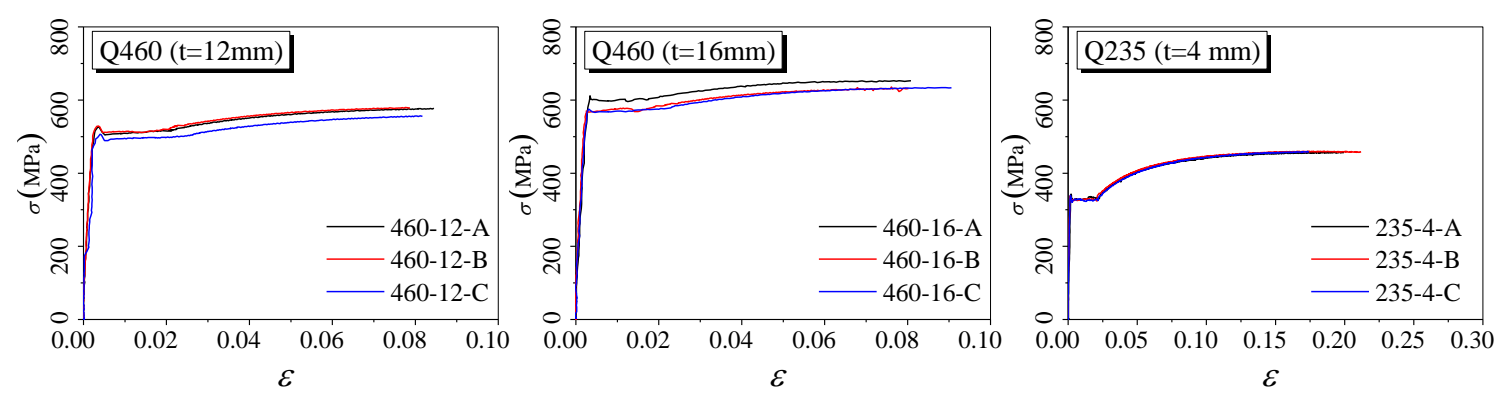

Fig. 5. Stress-strain curves extracted from coupon tests.

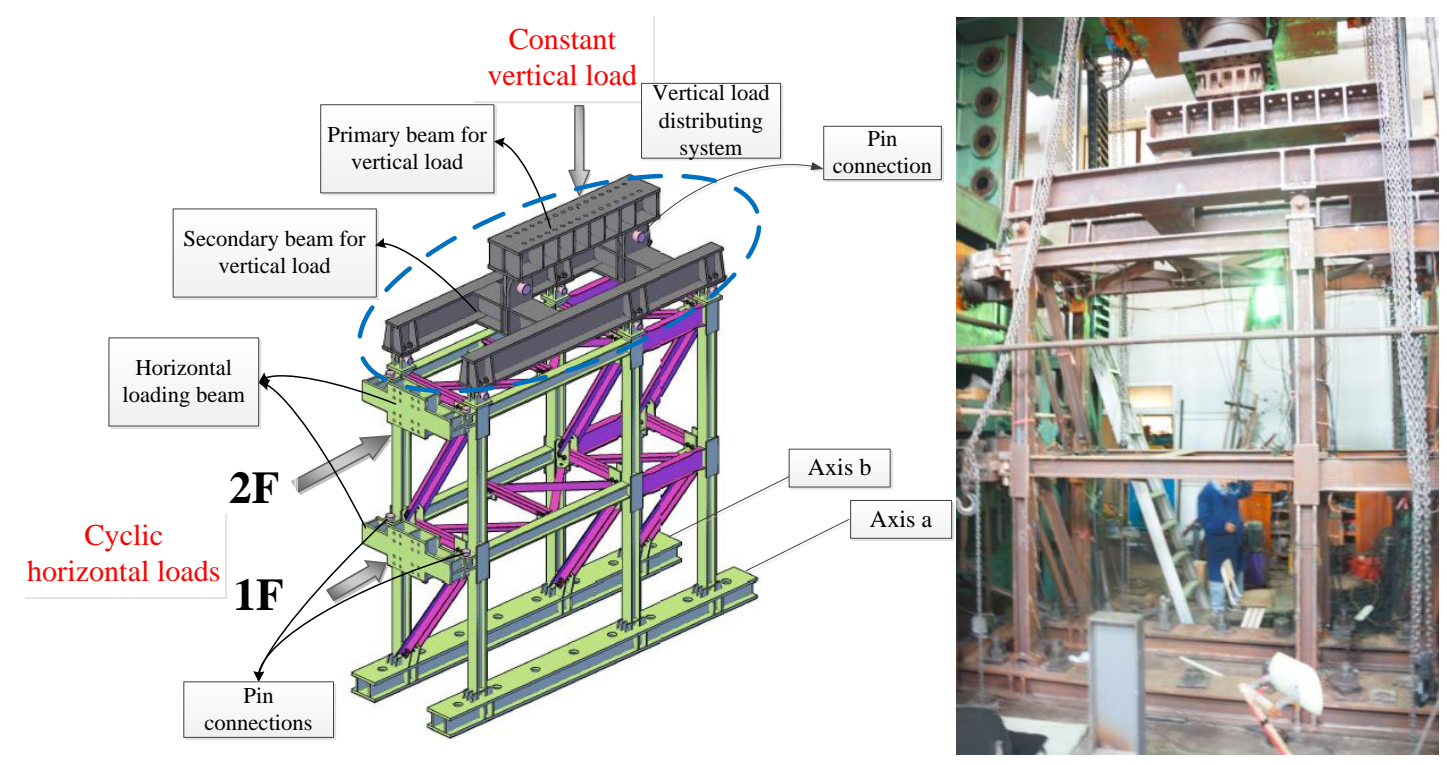

Fig. 6. Test setup. 


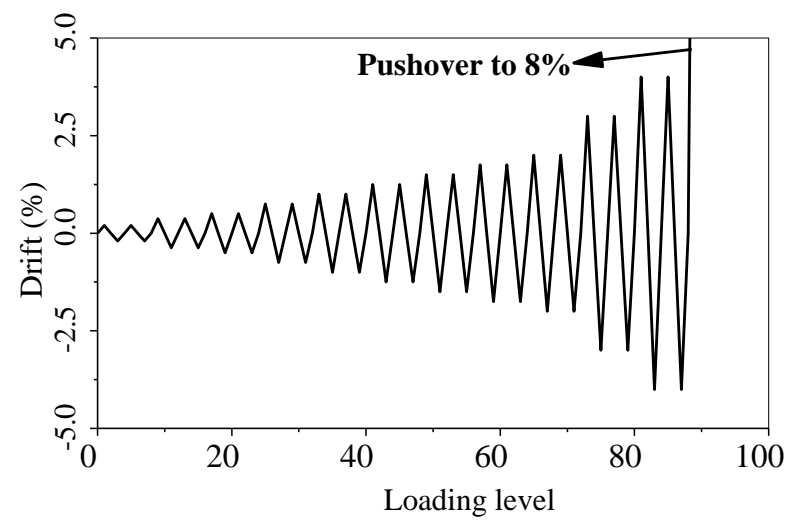

Fig. 7. Loading protocol.

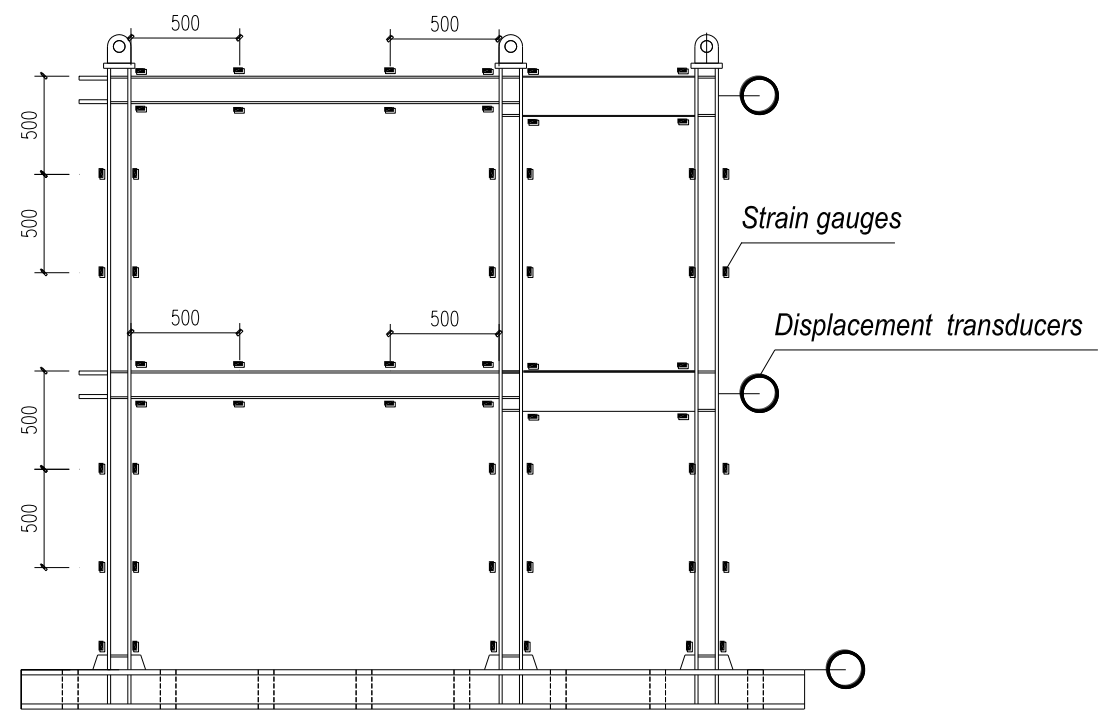

Fig. 8. Arrangement of strain gauges and story displacement transducers. 

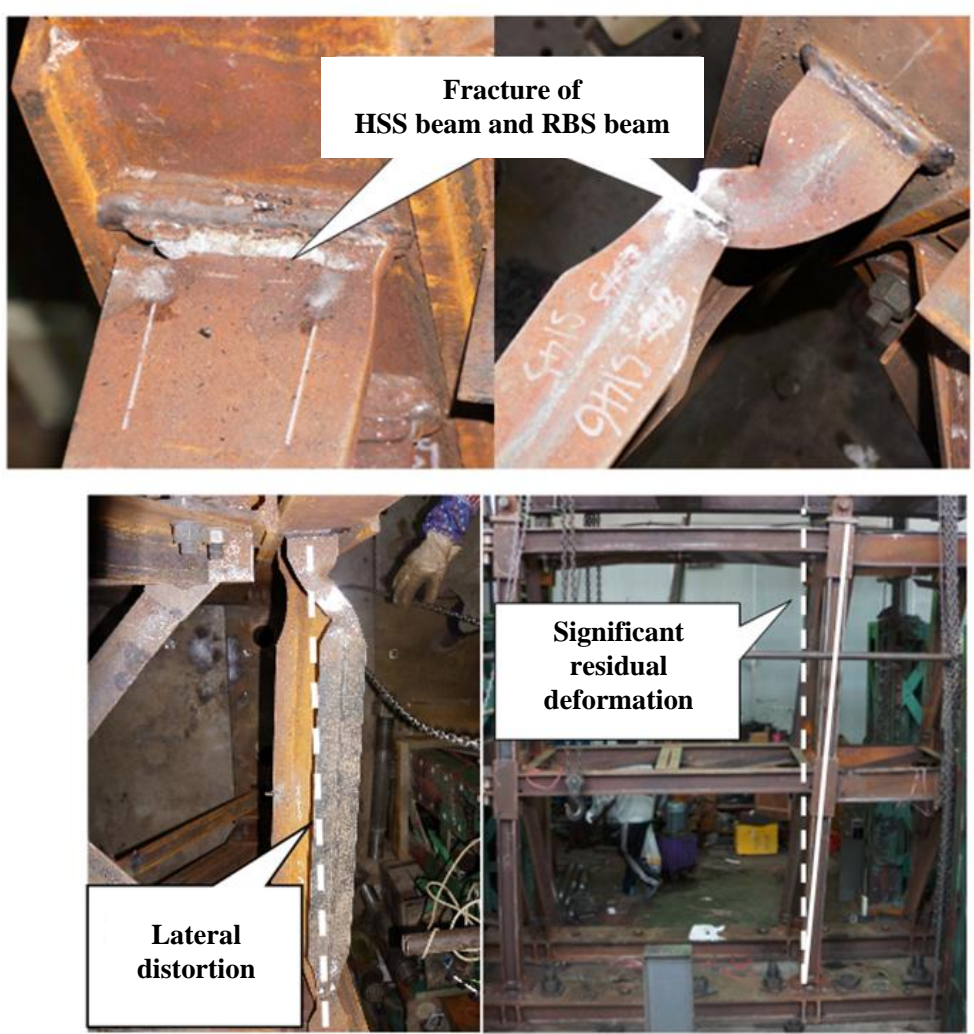

Fig. 9. Failure modes (after loaded to the drift of 8\%).
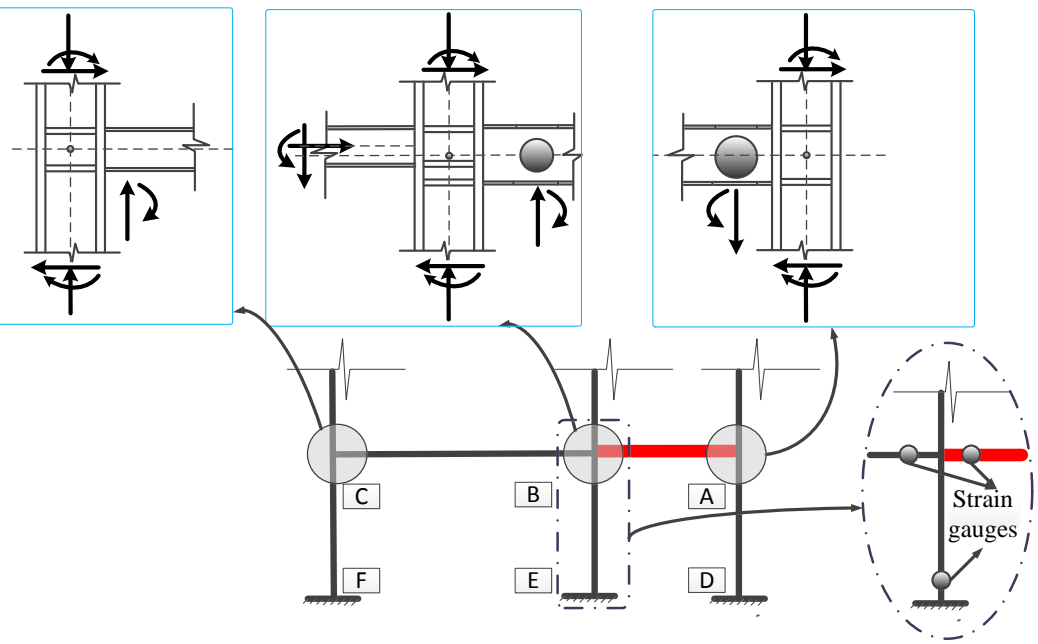

Fig. 10. Representative joints of the specimen. 

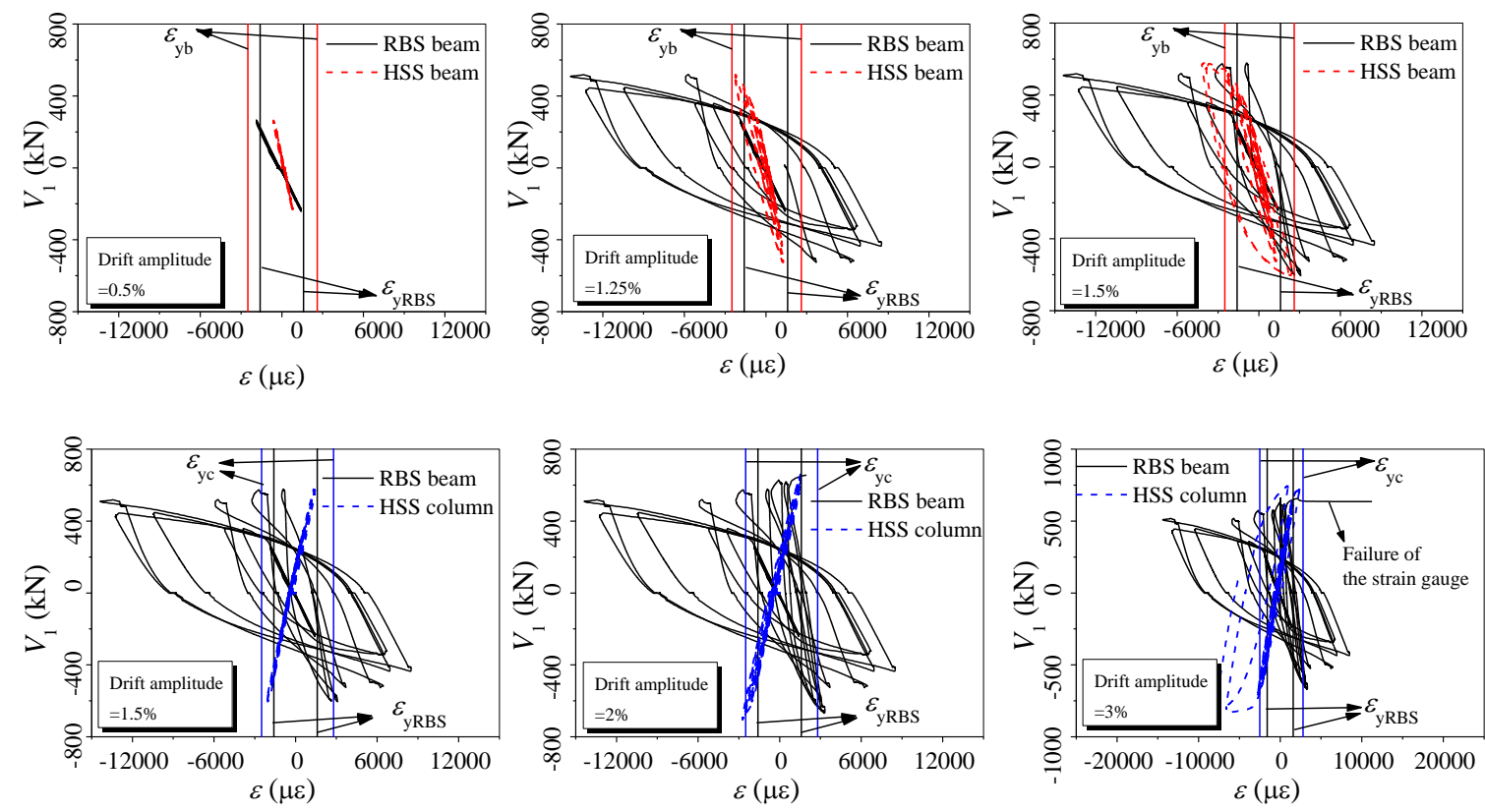

Fig. 11. Yielding sequence reflected by strain gauges data. 

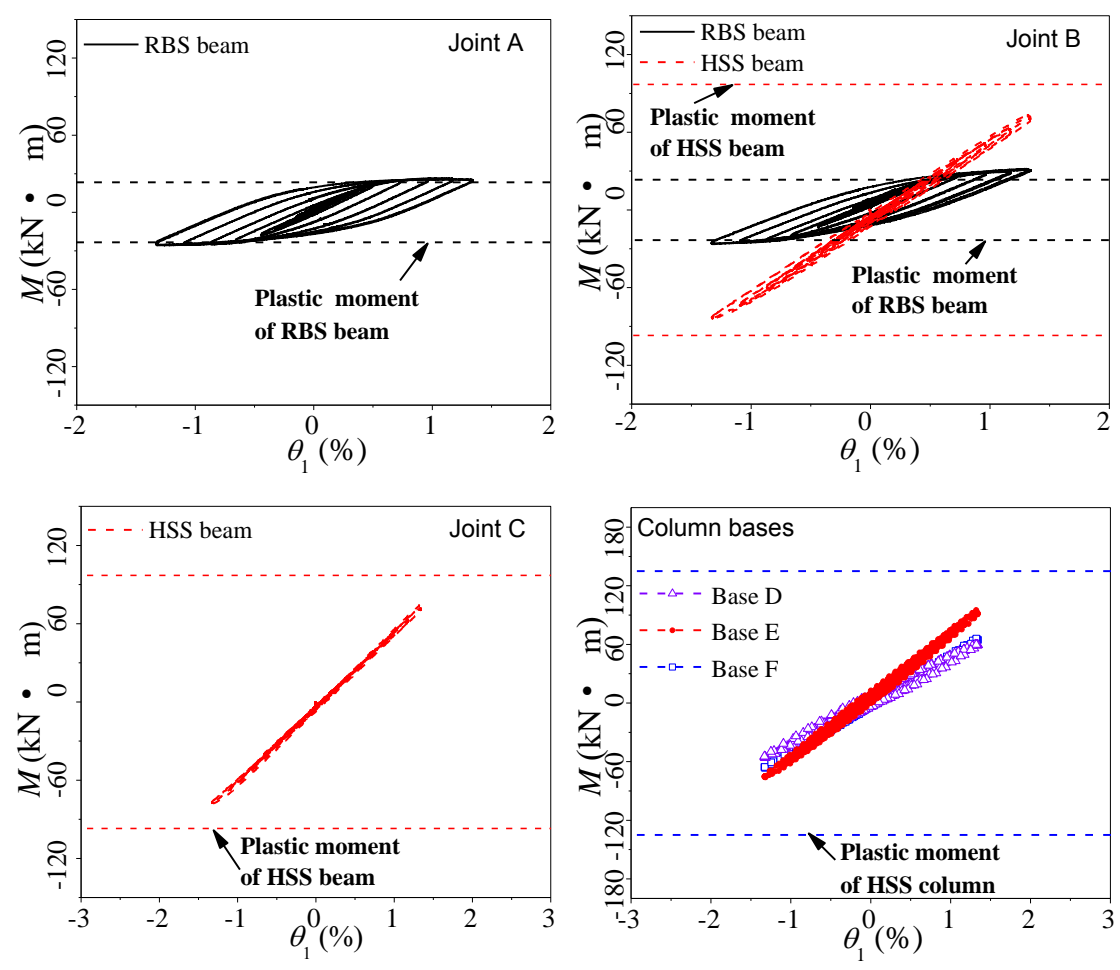

(a)
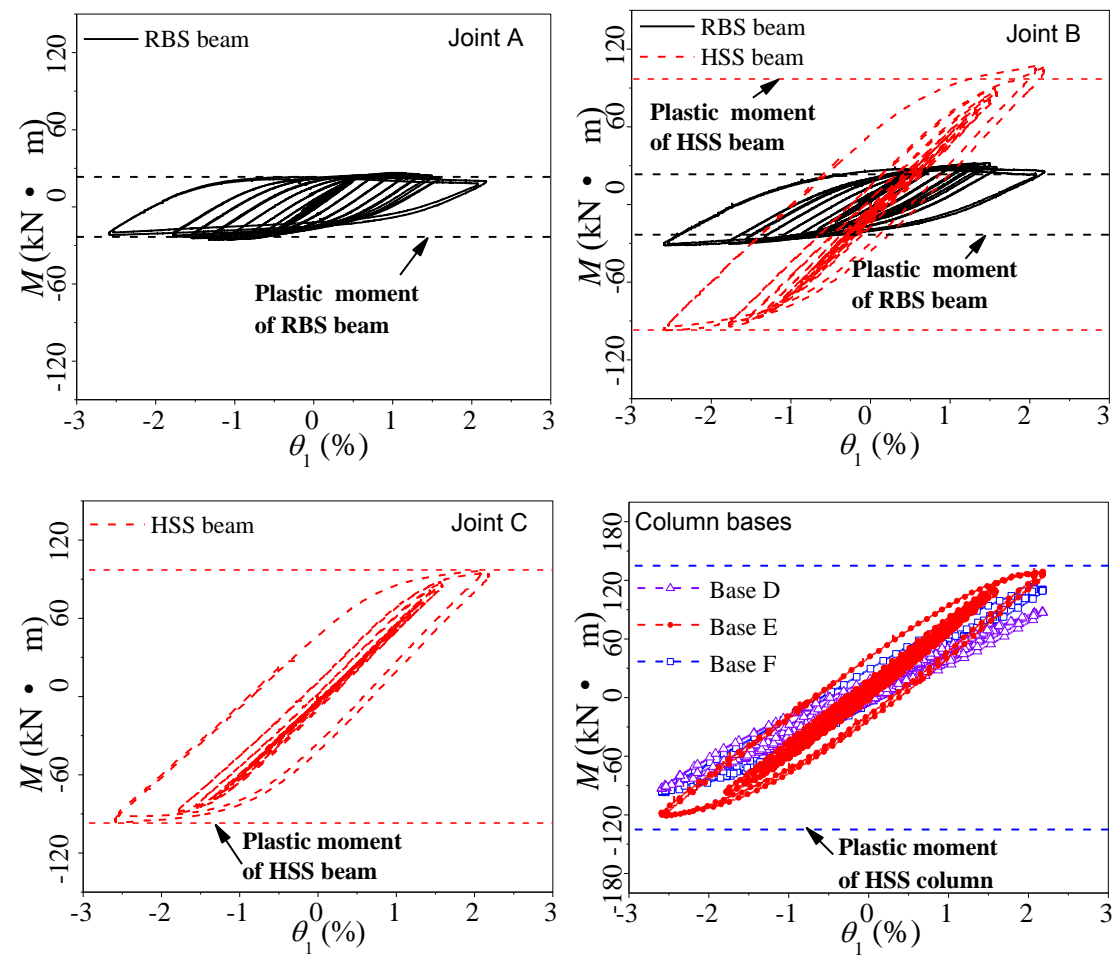

(b)

Fig. 12. Moment development: (a) Drift=1.5\%, (b) Drift $=3 \%$. 

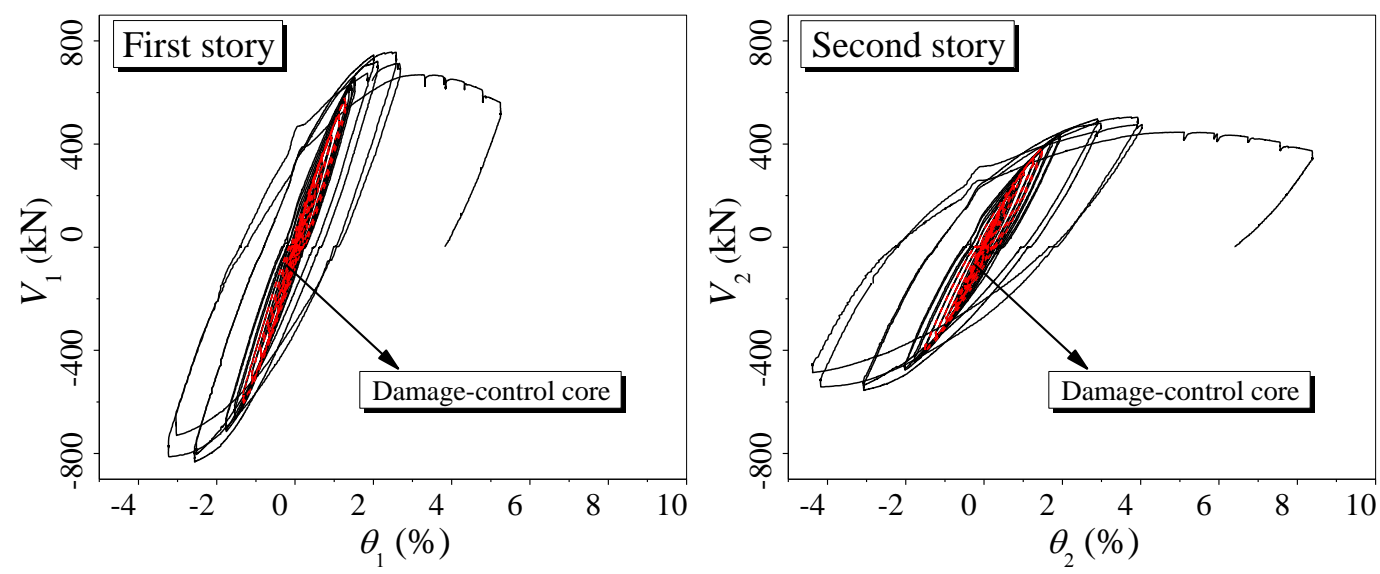

Fig. 13. Hysteretic curves.
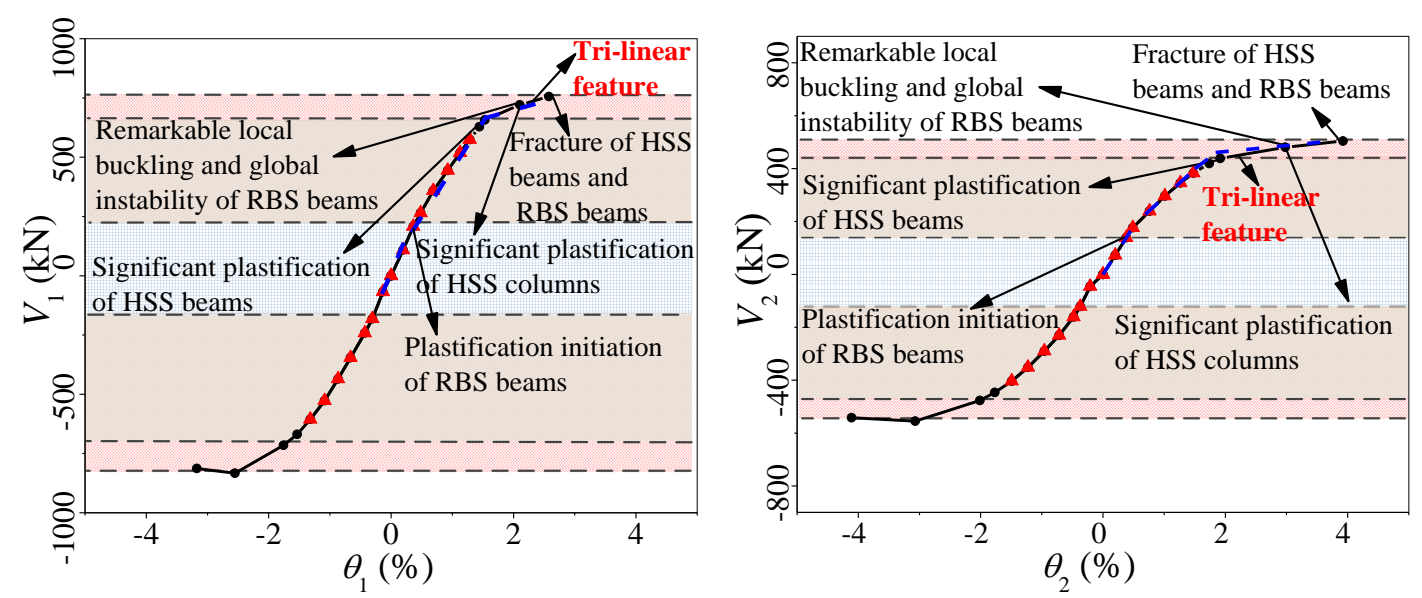

Fig. 14. Skeleton curves.

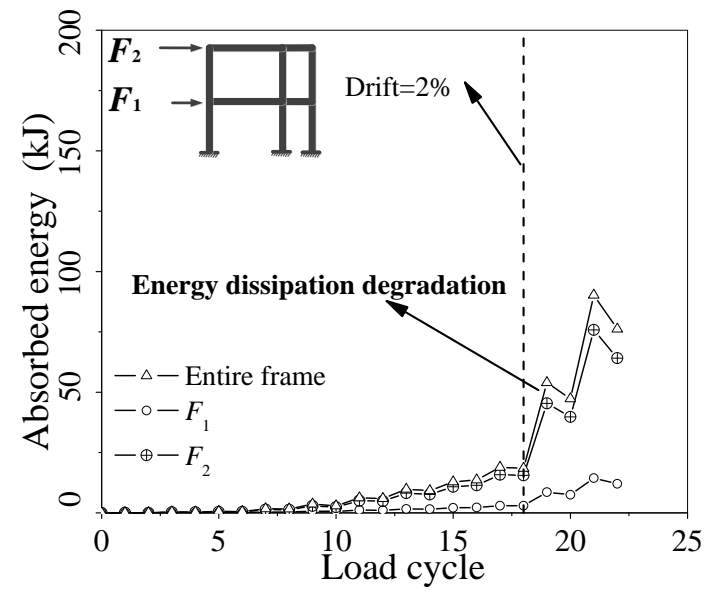

(a)

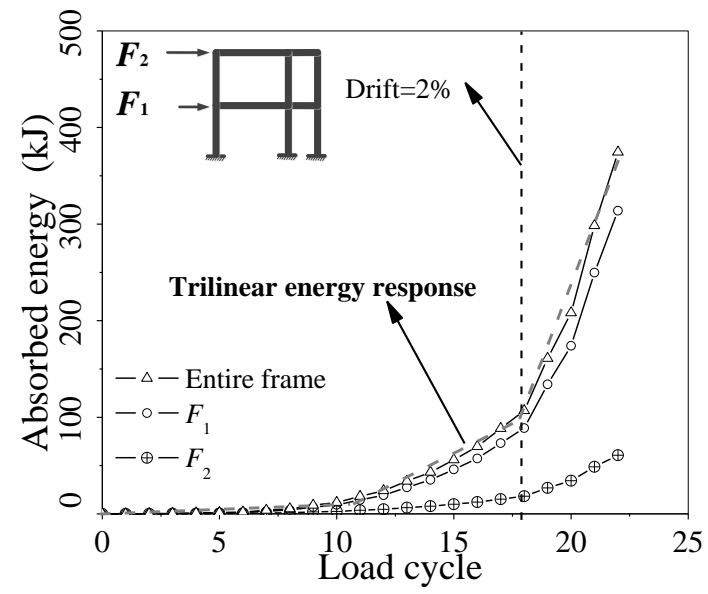

(b)

Fig. 15. Absorbed energy responses: (a) Absorbed energy in each cycle, (b) Accumulated absorbed energy. 


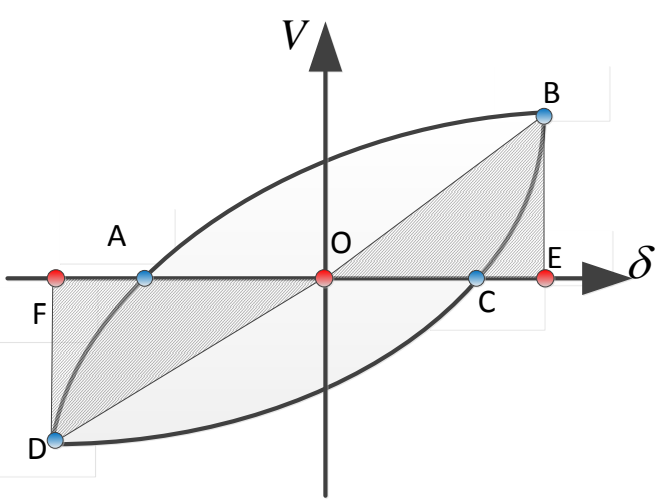

(a)

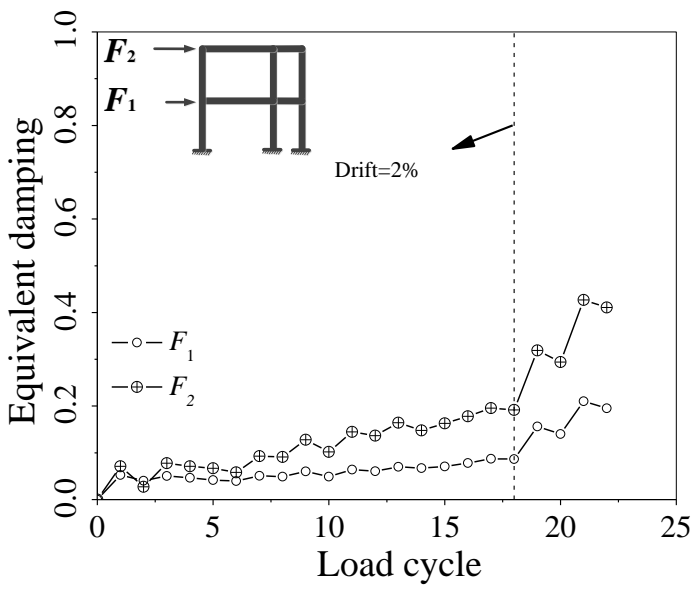

(b)

Fig. 16. Equivalent damping: (a) Definition of energy dissipation factor, (b) Equivalent damping.

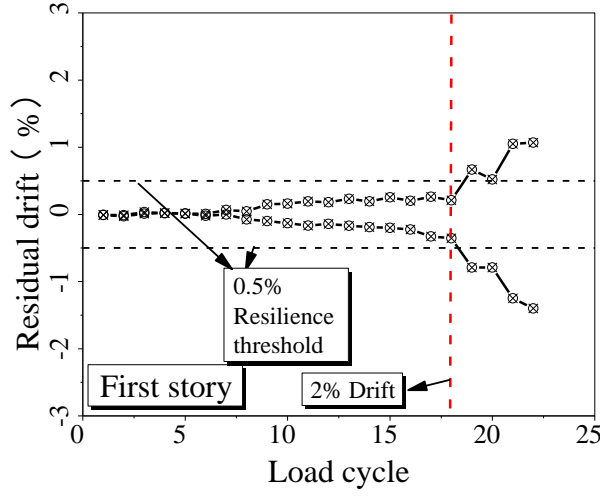

(a)

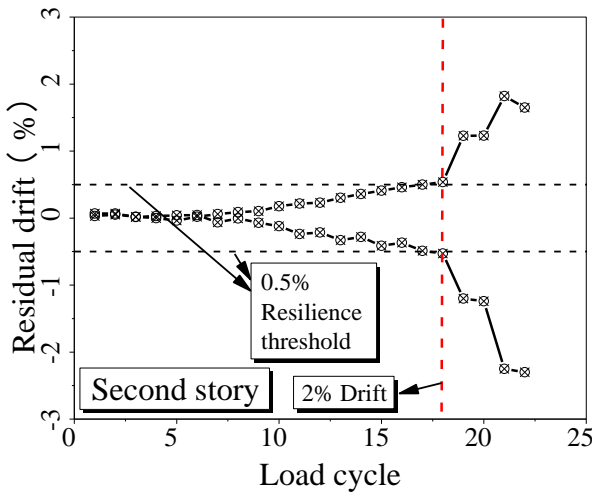

(b)

Fig. 17. Residual drift responses: (a) First story, (b) Second story.

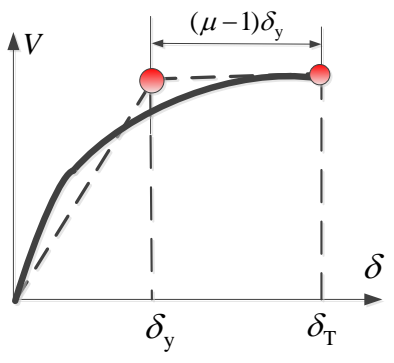

(a)

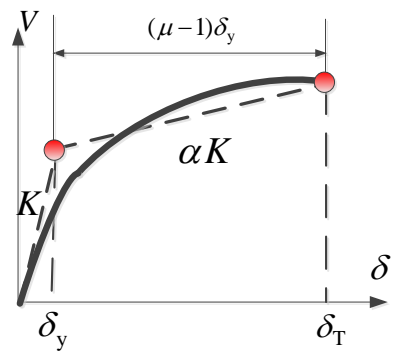

(b)

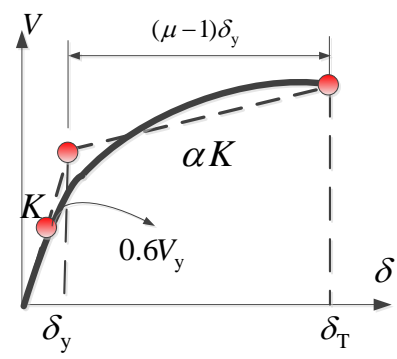

(c)

Fig. 18. Idealized approaches in different design guidelines: (a) EC8, (b) ATC-40, (c) FEMA-273. 


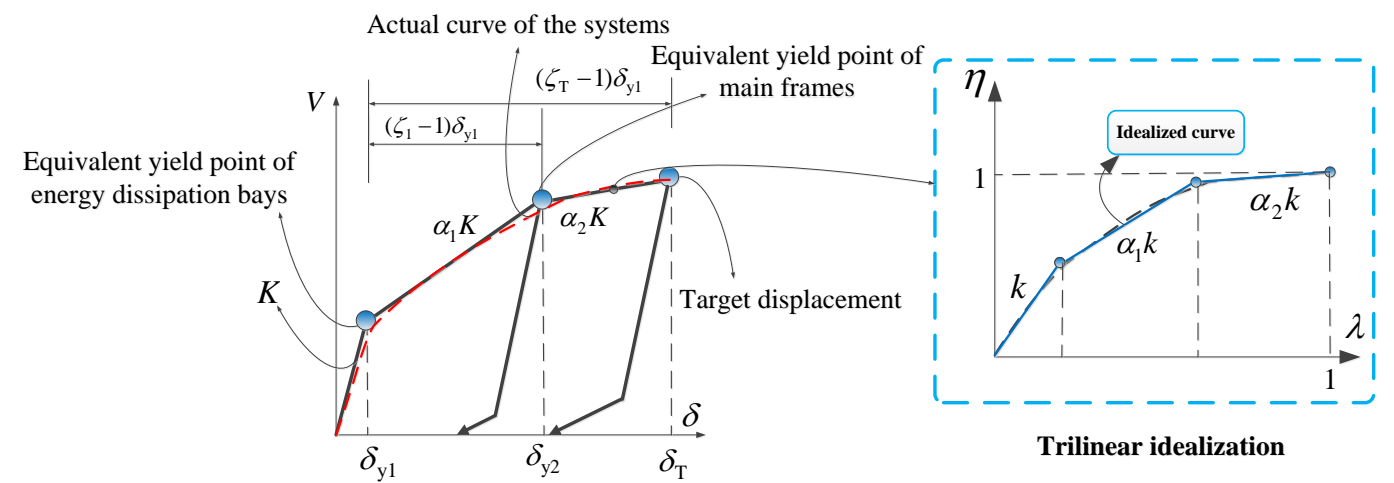

Fig. 19 Trilinear idealization of a load-displacement curve.
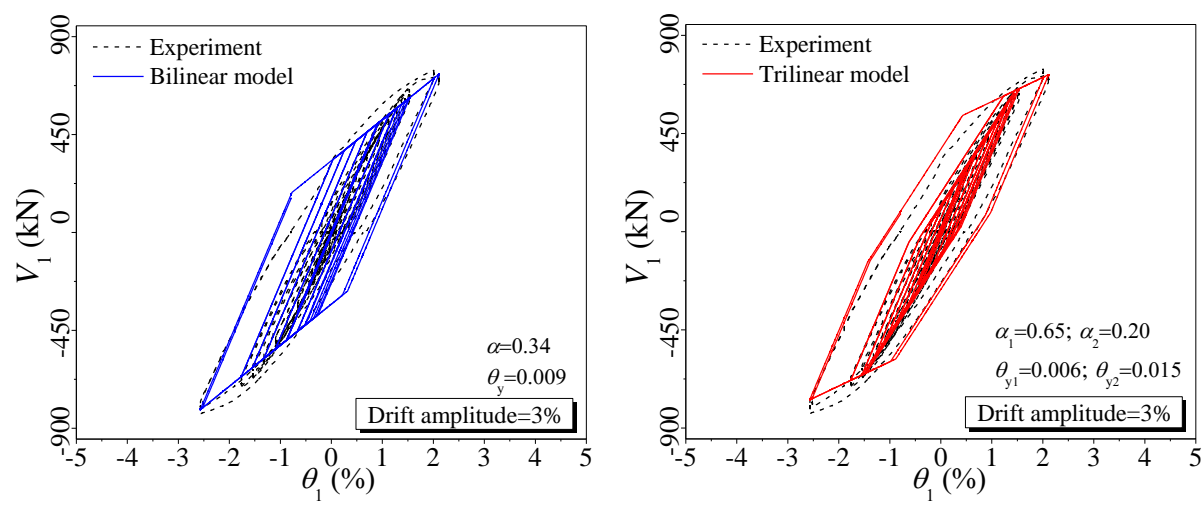

(a)
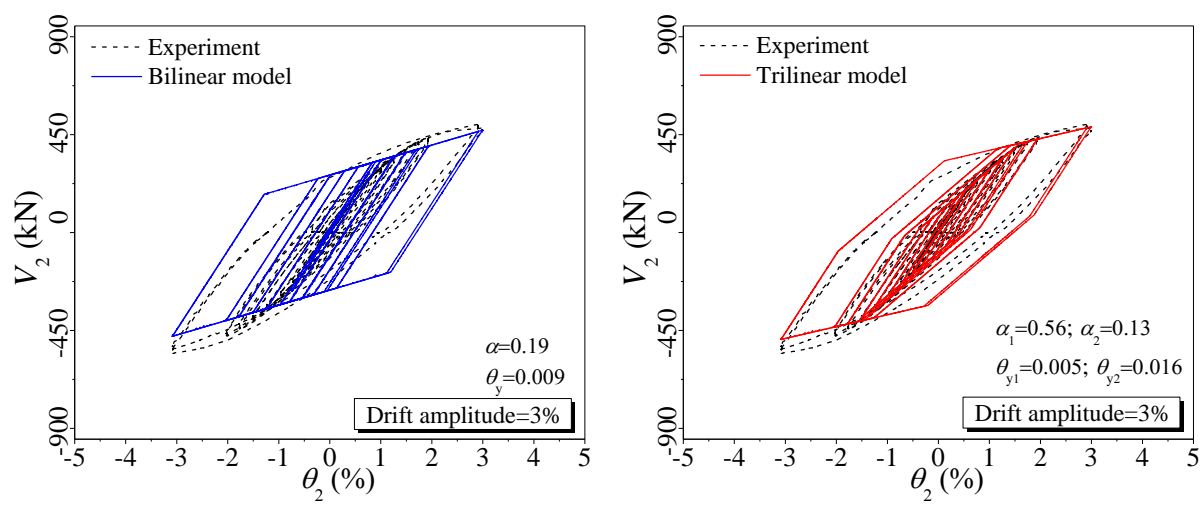

(b)

Fig. 20. Comparisons of different hysteretic models: (a) First story, (b) Second story. 


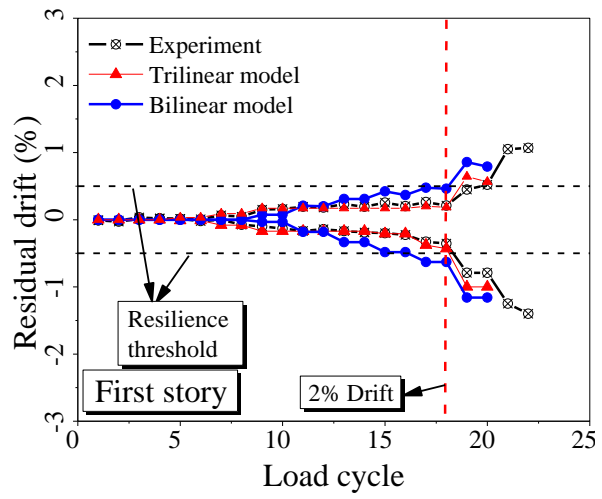

(a)

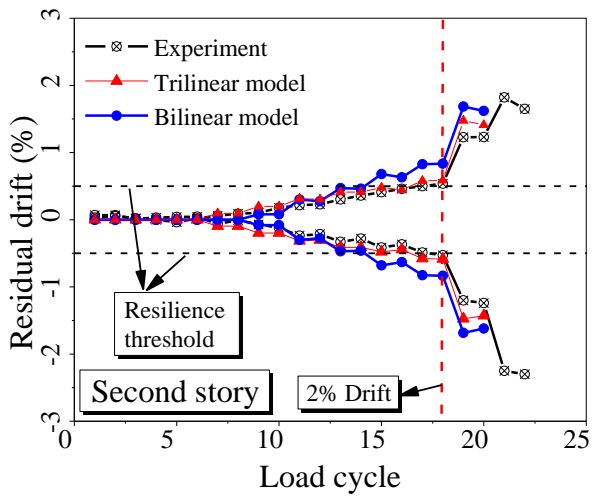

(b)

Fig. 21. Comparisons of residual drifts extracted from different models: (a) First story, (b) Second story. 


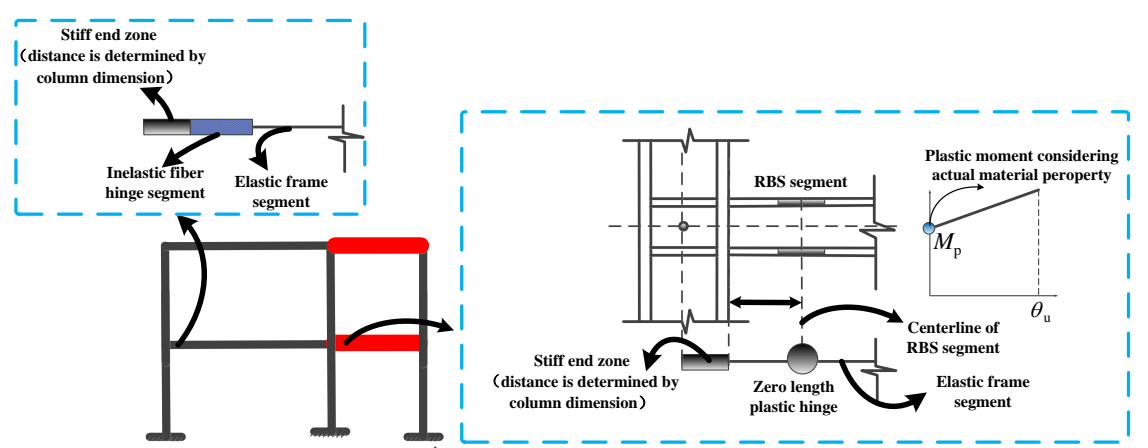

(a)
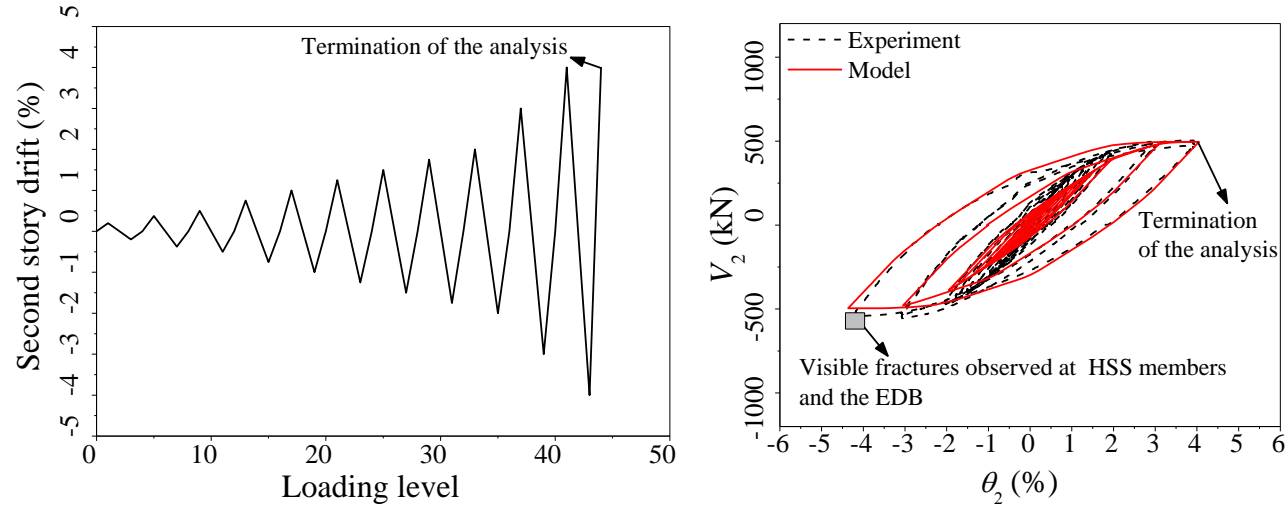

(b)
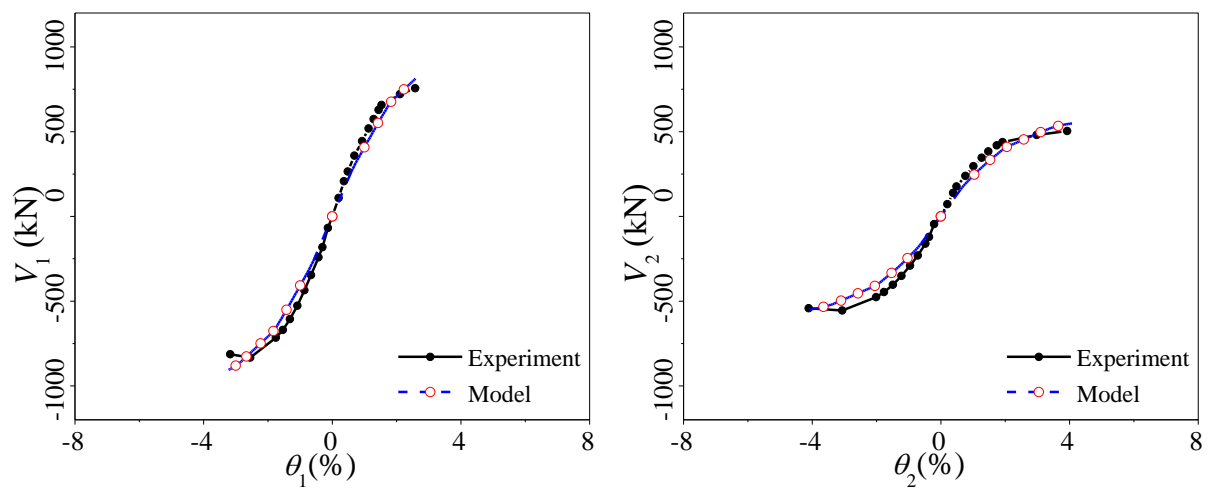

(c)

Fig. 22. Numerical model and validation: (a) Modeling detail, (b) Loading protocol for the analysis and comparison of hysteretic curves, (c) Comparison of skeleton curves 


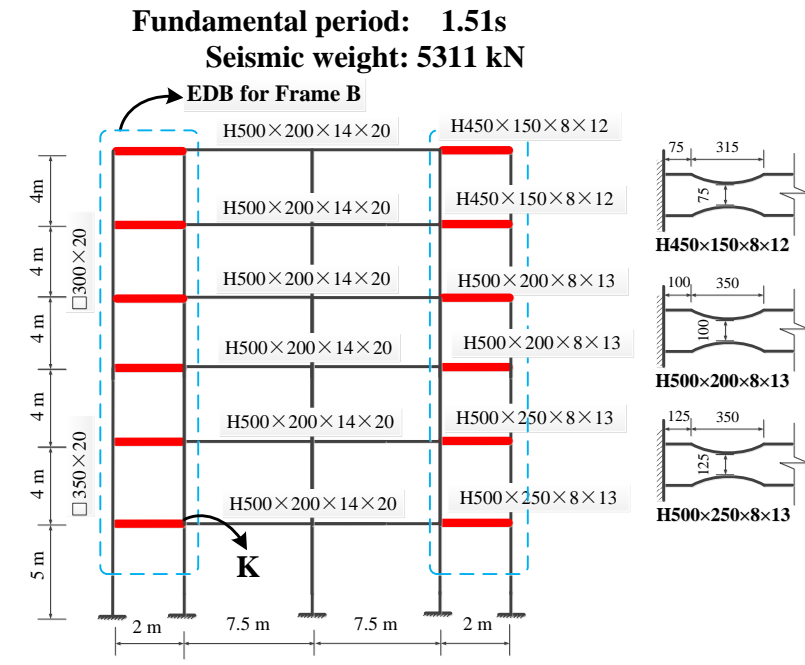

(a)

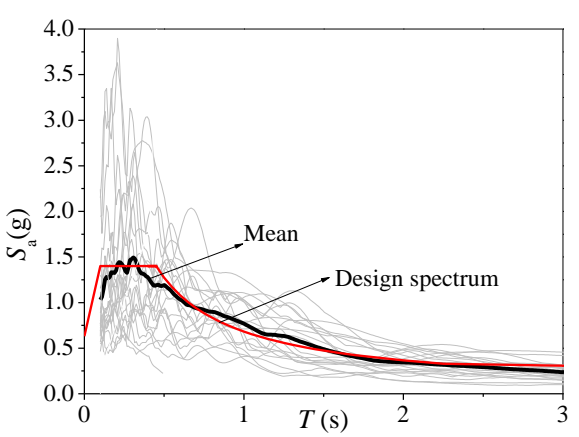

(b)

Fig. 23. Section arrangement and ground motions spectra: (a) Section arrangement, (b) Ground motions spectra.

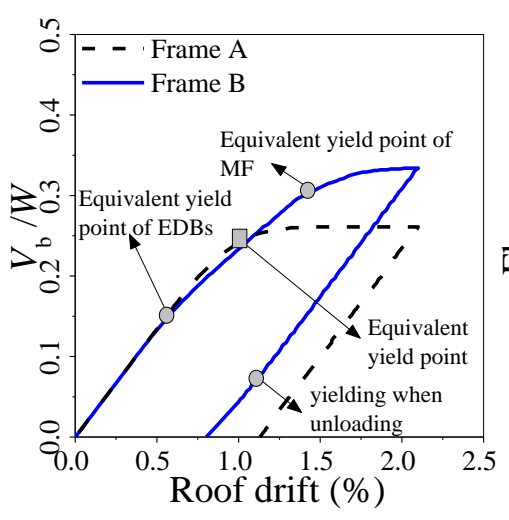

(a)

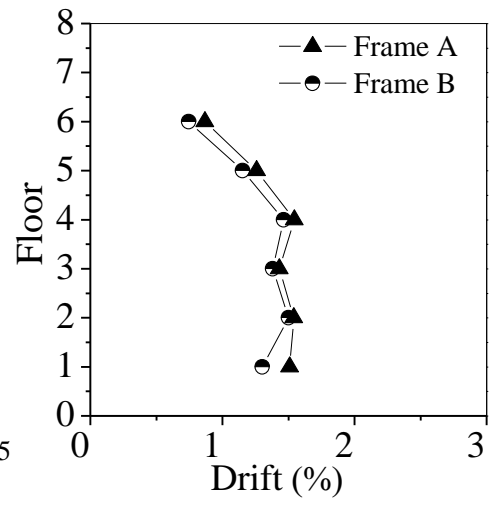

(b)

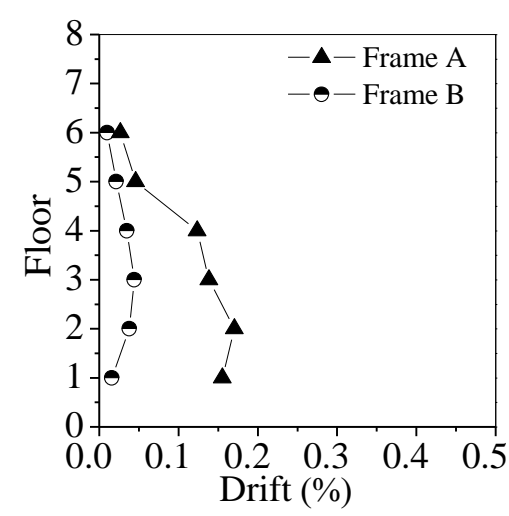

(c)

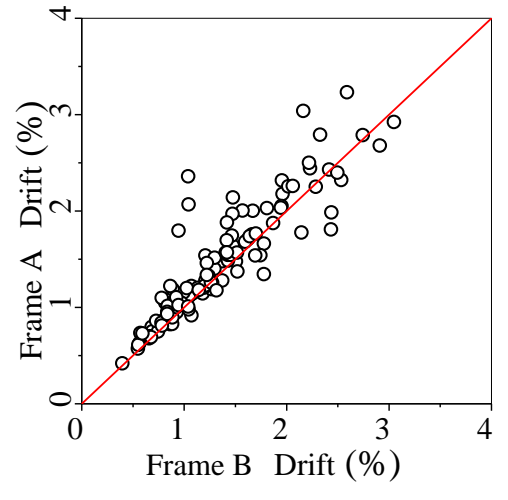

(d)

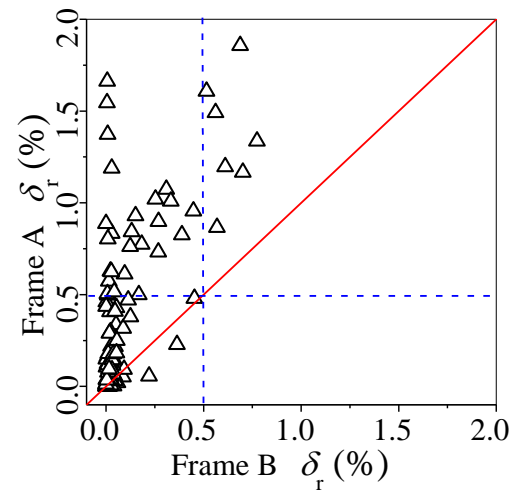

(e)

Fig. 24. Responses of prototype structures: (a) Pushover-unloading responses, (b) Median of maximum drifts, (c) Median of residual drifts, (d) Maximum drift comparison of Frame A and B, (e) Residual drift comparison of Frame A and B. 